\title{
Visualizing Social Acceptance Research
}

A bibliometric review of the social acceptance literature for energy technology and fuels

James Gaede 1 , lan H Rowlands 1

${ }_{1}$ School of Environment, Resources and Sustainability (SERS), Environment 2, University of Waterloo, 200 University Ave W., Waterloo, Ontario, Canada N2L 3G1

Corresponding author: James Gaede, Email: jrgaede@uwaterloo.ca;

Published in Energy Research \& Social Science, Vol. 40, June 2018, pp. 142-158.

\begin{abstract}
This paper conducts content and bibliometric analysis of 857 articles representing the knowledge domain for the social acceptance of energy technology and fuels. The objective is to identify basic trends and characteristics in the literature, identify current research fronts and pivotal papers therein, and map these fronts to their respective intellectual bases. We accomplish this by analyzing metadata, keyword use and citation networks within our dataset. We conclude with an evaluation of influence, structure, and collaboration and interdisciplinary dialogue in the field.

(C)

Keywords: social acceptance; energy and fuels; bibliometric analysis; research fronts; intellectual bases;

Funding: Research made possible by the financial support of the Natural Sciences and Engineering Research Council of Canada (NSERC) as part of the NSERC Energy Storage Technology (NEST) Network.
\end{abstract}




\section{Introduction}

Social acceptance of energy and fuels is a research area of increasing size and importance, situated approximately at the intersection of two much larger bodies of literature: the diffusion of new technology and/or innovations [1], and the social scientific study of energy and policy [2]. Using a definition provided by a recent conceptual review of the field, we can define acceptance as, "a favourable or positive response (including intention, behaviour and - where appropriate - use) relating to a proposed or in situ technology or socio-technical system, by members of a given social unit (country or region, community or town and household, organization)" [3]. Broadly speaking, the interest of the "knowledge domain" under consideration in this paper is in understanding and/or explaining acceptance of energy technologies and fuels.

This is an area of study that has experienced rapid growth in the past decade. Perhaps because of this growth, concerns have been raised over the methodological or theoretical rigour of the field [4], over the coherence of core concepts like NIMBYism [5-8], over the assumptions underpinning the interest in wind power in particular [9], and over the nature of acceptance itself [10]. It is unsurprising, therefore, that among the most influential papers in this field one finds a number of reviews and frameworks that aim to summarize and synthesize the many different theoretical and methodological approaches to social acceptance of energy technology and fuels [3,4,11-14].

Reviews and frameworks are useful for combining and condensing a wide range of research into a single, comprehensive structure, highlighting generalizable findings, pointing out gaps or weaknesses in a body of literature, and suggesting future directions for research. In short, they seek to produce order out of (what is perceived as) disorder and - intentionally or not - seek to enforce that order on future research in the field. The aim of this paper is not to produce another framework per se, but rather to provide a global and empirical visualization of the knowledge domain for the social acceptance of energy technology and fuels through a multi-step process involving content and bibliometric analysis. We conclude our paper by reflecting on the implications of our findings for understanding evolving structure and shifting influence, and for the promise of collaboration and interdisciplinary dialogue in the field.

\section{Domain Visualization}

The idea that a systematic, global, and theoretically and methodologically neutral perspective of a knowledge domain can provide insight into its structure and evolution is not new [15-17]. Visualization, in seeking to "reveal realms of scientific communication as reflected in the scientific literature and the citation paths woven by individual scientists in their publications," is one method for conducting such a domain analysis $[15,18]$. To do so, domain visualization makes use of citation analysis techniques that date back to the mid-20 ${ }^{\text {th }}$ century when the first scientific citation indexes were being developed [19].

One of the main goals of this analysis is to measure and assess similarity between works within an area of literature in order to identify 'sub-domains' in the larger knowledge domain (i.e., research communities within the field that are tightly connected). There are two main approaches to doing so: bibliographic coupling and co-citation analysis. Bibliographic coupling draws connections between papers based on the number of times they cite the same publications [20]. The strength of this connection thus increases with the number of common sources cited. Co-citation, on the other hand, draws connections between the cited references themselves, based on the times they are cited together by other papers [21]. The basic premise of either approach is that similarity between papers within a 
network (represented by the strength of connections between them) is likely to be higher within the sub-groupings in the literature than between them. Accordingly, we can proceed to identify communities within the literature after extracting the citation networks by running some basic network analysis algorithms (i.e., the Louvain community detection algorithm ${ }^{1}$ ).

Doing so can thus help to identify specialities within a knowledge domain. Information science generally distinguishes between two 'citation half-lives' of articles: classic articles with persistently high citations and transient articles that 'peak' in a short period of time [23,24]. The nature of influence and the significance of these types of articles is different, and is encapsulated by a related distinction between research fronts within a body of literature, and their respective intellectual bases. Price observed that scientists tend to cite more recently published papers, which he termed the 'immediacy factor' [24]. A research front consists of 40 to 50 commonly cited, recent articles, and thus represents 'state of the art' thinking in a research field. The intellectual base, on the other hand, consists of the older, 'classic' works that current research draws upon for theoretical and methodological structure. In short, according to Persson, "in bibliometric terms, the citing articles form a research front, and the cited articles constitute an intellectual base" [25]. A "speciality" within an intellectual field can thus be defined, according to Chen, as a "time variant mapping between a research base and its intellectual base" [23]. Both bibliographic coupling and co-citation analysis have been used to visualize research fronts $[23,26,27]$. In this paper, we use the former method to identify the fronts, and the latter method to identify their respective intellectual bases.

Domain visualization also allows us to measure the influence of certain authors, journals and papers in a way that goes beyond simple citation counts. Because domain visualization portrays a body of literature as a network, we can then calculate the centrality of the nodes (i.e., papers, cited references) within - a metric that quantifies the importance of a node's position in the network. The most commonly used centrality metric is betweenness centrality, a measure of the percentage of the number of shortest paths in a network to which a given node belongs [28]. Because the strength of connections between nodes in a network is often higher within sub-groupings than between them [29], nodes that are found along the paths that connect these groupings typically have higher betweenness centrality values, signifying that they are important in bridging two different communities. According to Chen, measuring centrality can allow a research to identify "pivotal points" between different specialities, tipping points in an evolving network [23].

In identifying specialities, key works, and the structure connecting them, domain visualization thus serves a pedagogical use as well. It can help new researchers become more familiar with the structure of field of knowledge and to identify existing areas of research that are most relevant to addressing the questions and problems they are looking to answer. It can also help those already working in the field to identify gaps and potential areas for collaboration and future research. We intend to use it to supplement existing perspectives on the knowledge domain for the social acceptance of energy and fuels with fresh insight on the influence, structure, and extent of collaboration in the field.

\footnotetext{
${ }^{1}$ The Louvain method for extracting communities from large networks is one method among others to represent modularity in the network. Modularity is essentially a measure of the density of connections between nodes nodes within communities have dense connections with others 'internal' to the community, and sparse connections with nodes considered internal to other communities [22].
} 


\subsection{Perspectives on the Social Acceptance Knowledge Domain}

To our knowledge, there have been no previous attempt at visualizing the knowledge domain for the social acceptance of energy and fuels using the bibliometric methods described in Section 2 - the closest we could find to comprehensive domain analysis was Sriwannawit and Sandström's large-scale bibliographic coupling analysis of the technology diffusion literature [1], and Sovacool's content analysis of over 4000 research articles published in leading energy journals between 1999 and 2013 [2]. Neither of these papers engage directly with the literature on social acceptance (Sriwannawit and Sandström do identify a 'technology acceptance' cluster in the diffusion literature, though it appears to be associated mainly with the information sciences literature on technology adoption in the workplace, i.e., the "technology acceptance model"). In the absence of large-scale bibliometric analysis of the knowledge domain, we can fall back on widely-cited, review-oriented papers - particularly those that offer "frameworks" - to understand how researchers working in this area understand the structure, main issues and future direction of the field.

Perhaps the widest-cited such paper is the introductory article to the 2007 special issue of Energy Policy on social acceptance by Wüstenhagen, Wolsink and Bürer [14], which introduces the three dimensions of social acceptance: socio-political, community, and market acceptance. The authors describe the defining characteristics of acceptance in each dimension, and provide examples of existing research. They describe socio-political acceptance as acceptance "on the broadest, most general level", noting that both policy and technology are subject to social acceptance of this nature [14]. Acceptance of this kind is associated with general public opinion, and the attitudes of key stakeholders and policy-makers [30]. Community acceptance they describe as the "specific acceptance of siting decisions and renewable energy projects by local stakeholders, particularly residents and local authorities" [14], and the arena in which debates around NIMBYism unfold [31]. Important considerations underlying acceptance in this dimension include perceptions of procedural and/or distributional justice with regards to project siting or renewable energy policy, and the extent of trust in project proponents, government or other key stakeholders. Lastly, market acceptance they associate with the process of market adoption of an innovation, and link to the decisions of consumers to purchase green electricity contracts [32], the decisions of investors to invest in wind power, or intra-firm acceptance of renewable energy innovation. They conclude by highlighting a number of suggestions for future research in each dimension, noting that understanding of market acceptance is particularly 'under-researched' at the moment [14].

Another widely cited framework paper is the 2005 article by Devine-wright, which reviews existing research on perceptions on wind power with the aims of critically assessing the literature and developing an "integrated, multidimensional framework to guide future work" in the field [4]. Based on the author's review of the literature, he identifies four research questions being addressed in the field and, on the basis of these, an additional two, overarching, "key" questions - does NIMBYism explain wind farm opposition, and does local involvement in wind farms increase local support? Devine-wright found that many studies were "poorly grounded" in social science theory, fragmented in their approaches to conceptualization and analysis and, as such, that it was difficult to identify the relative importance of different aspects in shaping perceptions of wind power. He finds four further "deficiencies" with the literature at the time: 1) Lack of research in non-industrialized countries; 2) A lack of valid and reliable quantitative methodological tools for operationalizing perceptions of wind farms; 3) Simplistic conceptualization of the notions of 'public' and 'community'; and, 4) A marked absence of explanatory theoretical frameworks. To correct these deficiencies, the author advocates for 
greater interdisciplinary collaboration, and incorporation of insights from environmental psychology and the concept of place to help ground research in existing social theory.

More recently, Upham, Oltra and Boso provide an updated version of the community / market / sociopolitical framework, and build on Devine-wright's call for integration and interdisciplinary collaboration. In this paper, the authors set out to bridge sociological and psychological perspectives on social acceptance by developing a comprehensive, "cross-paradigmatic" analytical framework based upon their personal involvement in and perceptions of the field [3]. To develop their analytical framework, they gathered a set of 39 articles, selected on the basis of an "academic database search" for the keywords [social acceptance or public acceptance or public attitudes and energy technologies or (a range of specific energy technologies)]. Based on the selected literature, and the authors' own experience in the field, they identify five main perspectives on the acceptance of energy technologies, associated with the disciplines of economics; sociology and human geography; social psychology; cultural theory; and 'frameworks and methods-driven work'. They then proceed to offer three general principles relating to social acceptance: 1 ) that the social acceptance of technology can be analysed at the macro, meso, and micro levels (e.g., country, community, or individual/organization); 2) that social acceptance at these levels can refer to different 'actor groups', such as consumer or citizen acceptance (i.e., public), stakeholder (with formal political objectives and an interest in the outcome) acceptance, or political acceptance (e.g., policy support), and; 3 ) individual acceptance is composed of "attitudinal elements, behavioural intentions and actual behaviours" (viz., acceptance entails both feelings toward and willingness to use or adopt energy technology). The authors conclude by discussing the challenges of generalizing findings from such a methodologically and epistemologically diverse field, suggesting that frameworks such as theirs can play an important role in facilitating interdisciplinary dialogue.

This short review is not intended to be comprehensive review of existing perspectives on the knowledge domain of social acceptance as a whole. Instead, we mention these three papers only to highlight the enduring importance of the community / market / social-political acceptance framework in conceptualizing the structure of the field, as well as the long-standing call for greater collaboration and interdisciplinary dialogue between researchers working in this area.

\section{Methodology}

We stated above that the objective of our research is not to produce another framework for social acceptance, but rather to supplement existing perspectives and provide fresh insight into the structure, main issues and future direction of the knowledge domain for social acceptance of energy and fuels. We then looked at three examples of influential perspectives on the field, highlighting the enduring importance of the community / market / socio-political schema and the longstanding call for greater collaboration and interdisciplinary dialogue. Accordingly, our research questions are:

1) What authors, papers, journals, topics and regions have been influential in shaping the knowledge domain of social acceptance?

2) To what extent do we find support for the "community / market / social" framework for conceptualizing social acceptance in the underlying structure of current research in the field?

3) To what extent do we find evidence of collaboration and interdisciplinary dialogue within the broader knowledge domain and between research fronts? 
Conducting content and bibliometric analysis on a comprehensive dataset of academic papers relating to social acceptance of energy technology and fuels will help us to address these questions by providing necessary metadata to identify trends and characteristics of the field; by identifying and describing specialities in the literature and uncovering the intellectual bases for each speciality; by identifying influential authors and journals (by publications and citations), and 'pivotal points' based on network centrality; by allowing us to examine the extent of collaboration and interdisciplinary dialogue between authors, journals and research fronts, and by visualizing the structure that connects them. Table 1 summarizes methods and data used to answer each research question.

Table 1) Summary of Research Questions, Methods, and Data

\begin{tabular}{|c|c|c|c|c|}
\hline $\begin{array}{l}\text { Research } \\
\text { Question }\end{array}$ & Method & Description & Shows & Data \\
\hline \multirow[t]{3}{*}{ Influence } & $\begin{array}{l}\text { Metadata } \\
\text { analysis }\end{array}$ & $\begin{array}{l}\text { Analysis of metadata } \\
\text { in original dataset; }\end{array}$ & $\begin{array}{l}\text { Trends, } \\
\text { characteristics }\end{array}$ & $\begin{array}{l}\text { Geography; Keyword use; Publication } \\
\text { year; }\end{array}$ \\
\hline & $\begin{array}{l}\text { Citation } \\
\text { statistics }\end{array}$ & $\begin{array}{l}\text { Data on citation } \\
\text { practices in original } \\
\text { dataset and extracted } \\
\text { citation network }\end{array}$ & 'Pivotal points' & $\begin{array}{l}\text { Local citations (number of citations from } \\
\text { papers within original dataset); }\end{array}$ \\
\hline & $\begin{array}{l}\text { Network } \\
\text { statistics }\end{array}$ & $\begin{array}{l}\text { Representation of } \\
\text { node importance to } \\
\text { the network }\end{array}$ & 'Pivotal points' & $\begin{array}{l}\text { Centrality (distance of travel to other } \\
\text { points in the network); Degree (number } \\
\text { of connections with other nodes); }\end{array}$ \\
\hline \multirow[t]{3}{*}{ Structure } & $\begin{array}{l}\text { Bibliometric } \\
\text { coupling }\end{array}$ & $\begin{array}{l}\text { Links between articles } \\
\text { citing same } \\
\text { references }\end{array}$ & Similarity & $\begin{array}{l}\text { Community extraction via Louvain } \\
\text { (density of connections); Top authors } \\
\text { (local citations); Top authors (centrality); }\end{array}$ \\
\hline & $\begin{array}{l}\text { Co-Citation } \\
\text { analysis }\end{array}$ & $\begin{array}{l}\text { Links between } \\
\text { references cited } \\
\text { together }\end{array}$ & Similarity & $\begin{array}{l}\text { Community extraction via Louvain } \\
\text { (density of connections); Top papers } \\
\text { (centrality); Top journals (frequency); }\end{array}$ \\
\hline & $\begin{array}{l}\text { Keyword } \\
\text { content analysis }\end{array}$ & $\begin{array}{l}\text { Links between } \\
\text { keywords listed } \\
\text { together on } \\
\text { publications }\end{array}$ & Similarity & Centrality; Degree; \\
\hline \multirow[t]{3}{*}{$\begin{array}{l}\text { Collaboration / } \\
\text { Dialogue }\end{array}$} & $\begin{array}{l}\text { Co-author } \\
\text { network }\end{array}$ & $\begin{array}{l}\text { Links between } \\
\text { authors listed } \\
\text { together on } \\
\text { publications }\end{array}$ & Frequency & $\begin{array}{l}\text { Degree; Weight (number of connections } \\
\text { between two nodes); }\end{array}$ \\
\hline & $\begin{array}{l}\text { Author- } \\
\text { research front }\end{array}$ & $\begin{array}{l}\text { Directed network } \\
\text { from author to } \\
\text { research fronts via } \\
\text { publications }\end{array}$ & Frequency & Degree; Weight; \\
\hline & $\begin{array}{l}\text { Research front } \\
\text { - journal }\end{array}$ & $\begin{array}{l}\text { Directed network } \\
\text { from research front } \\
\text { to journal via } \\
\text { publications }\end{array}$ & Frequency & Degree; \\
\hline
\end{tabular}

To build a dataset of articles upon which to conduct the bibliometric analyses, we began by reviewing influential articles in a preliminary literature search (some of which are noted above in Section 2.1), looking for important concepts or terms that might be common throughout the wider literature. Our 
preliminary search of the ISI Web of Science for the term 'acceptance' (restricted to the Social Sciences index and the ISI Web of Science' 'Energy and Fuels' category) returned 432 papers (as of September 2016). We then ranked these by citation count, and manually reviewed the titles and abstracts of top papers for common themes and word use. We also looked at the keyword frequency (there were 1063 unique keywords, including those supplied by the author and assigned by the Web of Science). The most frequently used terms were renewable energy, social acceptance, public acceptance, wind energy, CCS (i.e., carbon capture and storage), wind power, public perception, attitudes, public opinion and NIMBY.

Based on this initial investigation, it was clear that there were two key components to the definition of our search, the 'acceptance' component and the 'actor' component (or who is doing the accepting), with several different words being used for each. Excluding technologically-specific terms (like wind or carbon capture and storage) was deemed important for maintaining comprehensiveness. We then conducted a new search of the Web of Science 'Energy and Fuels' category for topics (including text in the title, abstract and keywords) containing any of the following actor-component words ('social', 'public', 'market', 'community', or 'polit*') used in conjunction with any of the following acceptance-component words ('accepta*', 'perception', 'attitud*', 'opinion', or 'opposition'). We restricted this search to the Social Sciences Citation Index, and to material published in English up to 2015. This search returned 857 articles.

It is important to note that our method for building this dataset may not have captured all the literature that might be considered part of the knowledge domain by those intimately familiar with the field, just as it may have included some literature that might not. Our intention was not to create an exhaustive database, but rather to achieve a balance between inclusion and exclusion that would capture most of the work in the field at the moment and without obscuring the influence and structure within that work behind larger fields or unrelated work. Therefore, we encourage readers to focus less on specific rankings and quantitative measures for authors and journals, etc., and instead on the general structure and influence suggested by them. Furthermore, our analysis of the content of different groupings in the literature is based upon network and keyword analysis, and thus provides a limited perspective on conceptualization, operationalization and findings on social acceptance the field that non-bibliometric systematic review is better suited to addressing. Also, it is important to note that we ran our search criteria both without 'opposition' and with 'public support' to test inclusiveness and ensure against possible bias in our results. The search without opposition returned only 35 fewer papers while the search with public support returned 945 more. Subsequent exploratory content analysis of the additional papers in the latter search did not demonstrate a close connection with social acceptance (keywords such as accept*, opinion and attitude did not appear once in the additional papers), indicating that public support was too broad a search term to target the field of our interest.

Analysis of this dataset was performed in three separate steps: ${ }^{2}$ 1) a preliminary, descriptive analysis of the literature, looking at publication years by country, top journals, and top cited papers; 2 ) an analysis of the citation network contained in the original dataset (including a bibliographic coupling and keyword analysis to identify and describe research fronts and influential papers, and co-citation analysis to identify intellectual bases for each research front, with additional review of top papers and journals); and, 3) analysis of co-author, author-journal, author-research front and research front-journal networks

\footnotetext{
${ }^{2}$ It should be noted that citation counts
} 
to examine collaboration and interdisciplinary dialogue. Extraction and analysis of the citation networks was performed using Sci2, and visualization of the networks was done in Gephi and Adobe Illustrator. We present the results of these three steps in Sections 4.1, 4.2 and 4.3 below, and discuss the findings with respect to our research questions in Section 5.

\section{Results}

In this section, we present the results of our three-step analysis, describing some basic characteristics of the literature dataset in Section 4.1; identifying and describing facets of the citation network (i.e., research fronts and intellectual bases) in Section 4.2; and exploring the extent of collaboration and interdisciplinary dialogue in Section 4.3.

\subsection{Basic Characteristics}

The 857 articles comprising our literature dataset were published in 33 different journals, though almost $2 / 3$ rds (60\%) were published in Energy Policy, the leading journal by far (at least by quantity of publications). The next four journals where Renewable \& Sustainable Energy Review (9.5\% of articles); Renewable Energy (4.1\%), International Journal of Greenhouse Gas Control (4.1\%), and Applied Energy (3.3\%). Overall, $81 \%$ of all articles were found in the top five journals. The top five cited works were [14 (339 citations), 4 (283),33 (275),34 (245),7 (238)]. A total of 2008 unique authors were included in our dataset. The top five authors by total publications were M. Siegrist (12); P. Upham (12); P. Ashworth (9); M. Wolsink (8); and S. Shackley (7). The top five authors by 'first author' publications were: P. Upham (7); A. Verbruggen (6); M. Wolsink (5); J. Ladenburg (5); and JK Kaldellis (4). Only 82 (4.1\%) were first author on two or more papers.

The earliest paper in our dataset was published in 1982, though the bulk of the literature (90\%) was published between 2006 and 2015. In fact, looking at the chart of articles published per year provided in Figure 1 below, we can see that publications on social acceptance of energy and fuels remained largely static in the two final decades of the $20^{\text {th }}$ century, before growing dramatically in the early 2000 s. We used the reprint author's address to categorize the publications by country (only 16 of the 857 articles did not provide a reprint author address). In total, 58 countries were identified. Just under $50 \%$ of all articles where published in the top five countries: USA (16.3\% of articles); England (12.7\%); Netherlands (7.1\%); Australia (4.9\%); and Canada (4.9\%). Approximately $80 \%$ of the articles were published in the top 16 countries. Figure 1 breaks the growth in publications down by the top five countries and the 'rest of the world' (ROW). It is clear that until 2009, the share of publications from the top six and the ROW was more or less equal, with the ROW countries producing more publications than the top six countries combined thereafter. 


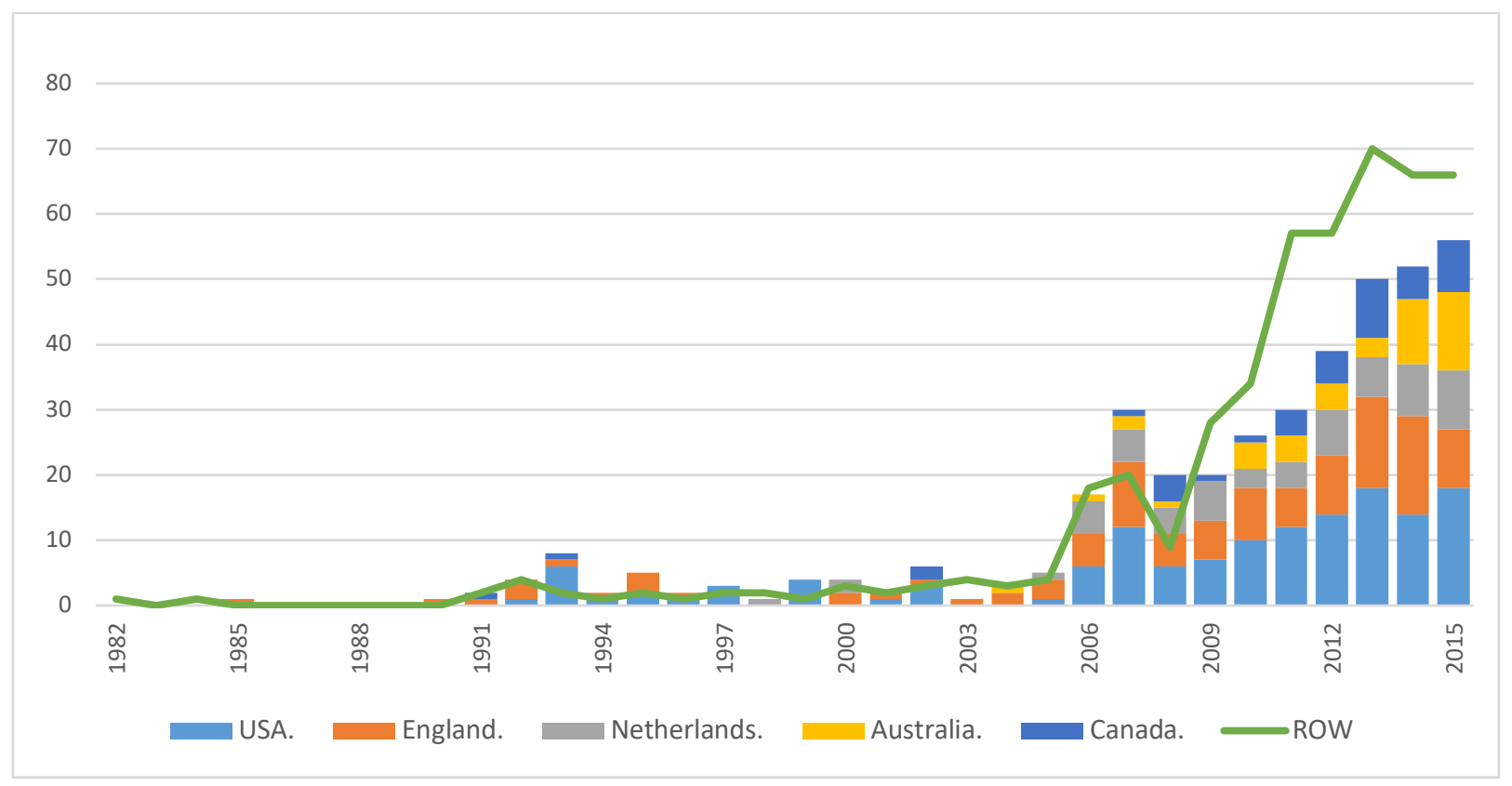

Figure 1) Publications by Year and Region

We can also see from this figure that there were two 'blips' in the publication trend - a smaller blip in 1993 and a larger one in 2007. This figure also seems to indicate three 'periods' in the literature. Prior to the 1990s there are only three publications in the dataset. In the 1990s, it appears as if a lower 'plateau' of around 5 articles per year was reached, before the rapid growth period began around 2006 the dataset contains 89 articles published between 1990 and 2005, and 765 between 2006 and 2015 . We compared these trends with those for the 'Energy and Fuels' research category overall and found growth trends to be approximately the same.

A total of 3508 keywords ( 1852 unique) were given, 1131 by authors ( 809 unique) and 2377 by the Web of Science (1043 unique). The top terms (based on frequency of use) across both author-supplied and Web of Science keywords were attitudes; renewable energy; social acceptance; power; policy; public acceptance; perceptions; public-attitudes; energy; and wind energy. The top terms in the authorsupplied keywords alone were renewable energy; social acceptance; wind energy; public acceptance; attitudes; wind power; CCS; public perception; climate change; and carbon capture and storage.

\subsection{Citation Networks}

Extraction of the citation network indicated that publications in our dataset made a total of 31,742 citations. This list includes all unique references cited in the papers included in the original database. Within the citation network, governmental institutions are the most widely cited (e.g., 370 cited sources under different permutations of the International Energy Agency), though the variety in formulations of organizational name and report title make summarizing the influence of individual reports difficult. Overall, a total of 17,135 unique publication titles (e.g., book titles, journal titles) were present in the citation network. The most commonly cited publications were academic journals, the top five being Energy Policy (2036 citations); Renewable and Sustainable Energy Reviews (572); Energy (305); Renewable Energy (279); and Applied Energy (208). 
With regards to individual authors, it is important to note that citation records only list the first author of the paper and that references are not always formatted the same across papers (for example, one paper might reference a paper as authored by 'Devine-Wright, $\mathrm{P}$ ' while another might reference it as authored by 'Devine-Wright, P.'). Accordingly, summary statistics for citations of unique papers by author (and, therefore, total papers cited per journal) are not $100 \%$ accurate, and data on co-authorship is not available. Furthermore, citation records also include self-citations. This may inflate rankings by cited works, but this should not affect the citation network analysis as connections are drawn between papers on the basis of similar citations, and influence measured via these connections (and not on simple citation counts).

To examine data reliability and produce summary statistics on influential authors, we sorted the list by number of unique works cited ${ }^{3}$ and extracted the top 200 individual authors (i.e., excluding citations of the organizations like the International Energy Agency or European Commission). Within this list there were 17 duplicate author name formulations. We combined the works cited for each duplicate ${ }^{4}$ and sorted the list by number of works. We then compared the changes in ranking from the original citation list (excluding duplicates) to the de-duped list. Overall, ranking changes were relatively minimal, with only 10 authors in total moving up or down a magnitude of 10 or more spots. Of the original 10 authors with the greatest number of cited works, six remained in the top 10 after de-duping (of the original top 20, 15 remained). We then extracted the author-journal network from the list of 2226 unique works authored by the top 200 individual authors. The list of the top five journals was similar to that for the whole citation network, though Applied Energy dropped from fifth to eighth, while the Journal of Environmental Psychology moved up from twelfth to fifth. This suggests that while number of unique works cited may not be accurate for each author or journal, they are nevertheless still representative of general influence ranking within the literature. The top 20 authors by unique works cited (after deduping) are presented in Table 1.

Table 2) Top 20 Individual Authors in the Citation Network, by Unique Publications

\begin{tabular}{|l|c|c|}
\hline Author & Works & $\begin{array}{c}\text { De-duped } \\
\text { Rank }\end{array}$ \\
\hline Devine-wright P & 54 & 1 \\
\hline Kaldellis Jk & 48 & 2 \\
\hline Ashworth P & 41 & 3 \\
\hline Wolsink M & 41 & 4 \\
\hline Sovacool Bk & 38 & 5 \\
\hline Slovic P & 35 & 6 \\
\hline Renn O & 30 & 7 \\
\hline Sjoberg L & 28 & 8 \\
\hline Upham P & 26 & 9 \\
\hline Stirling A & 25 & 10 \\
\hline
\end{tabular}

3 'Works cited' is a much broader category than peer-reviewed papers, including all varieties of academic outputs that might be cited in a research papers - books, book chapters, newspaper editorials, and so on. Hence, the large discrepancy between 'works' in the citation network, and papers in our original dataset.

${ }^{4}$ We did not consider if the cited works were unique however, so the totals presented in Table 1 could be slightly inflated. The actual figures for unique works by author are likely to lie between the original and de-duped works cited counts. 


\begin{tabular}{|l|l|l|} 
Verbruggen A & 25 & 11 \\
\hline Kempton W & 24 & 12 \\
\hline Ajzen I & 23 & 13 \\
\hline Stern Pc & 23 & 14 \\
\hline Shove E & 22 & 15 \\
\hline Toke D & 22 & 16 \\
\hline Brunsting S & 21 & 17 \\
\hline Siegrist M & 21 & 18 \\
\hline Walker G & 21 & 19 \\
\hline Itaoka K & 20 & 20 \\
\hline
\end{tabular}

\subsubsection{Research Fronts}

To identify the research fronts in the literature, we extracted the bibliographic coupling network from the citation network and deleted any isolate references (i.e., those not connected to any other) in the network. This left 780 papers - most of the original 857 papers, but excluding some that did not have any common references with other papers. To further simplify this network, we filtered out papers with five or less linkages and removed isolates again, leaving a total of 343 papers with 1605 connections between them. We then ran the Louvain community detection algorithm (see footnote 1 ). The top seven groupings (by size) comprised $82 \%$ of the 343 publications. We exported the graph for visualization in Gephi, and filtered out nodes not connected to the 'giant component' (i.e., any marginal papers related to each other, but not to the main body of literature), leaving 290 of the most highly interconnected papers. We then ran the Force Atlas 2 visualization algorithm, coloured nodes by community, and based node size on local citations (i.e., citations within the original literature dataset). The top three cited papers per grouping are coloured more darkly and labelled. The resulting visualization is displayed in Figure 2, and a summary table in Table 3 (Appendix A shows a comparison of the visualization with node size based on citations versus node size based on centrality). We will focus on the top seven groupings in the ensuing analysis (comprising 281 papers, or $\sim 97 \%$ of the main body of literature), as the other groupings had only two or three members after all the filters were run.

For each group, we looked at the publication years, journals, and types (i.e., article or review), top papers (by local citations and centrality), and top authors (by authored works). Content analysis of the research front groupings was conducted by looking at keyword usage, both in terms of the most commonly used keywords and the co-occurrence of keywords. Analysis of keyword co-occurrence provides another network visualization, allowing us to visualize not only the most commonly used keywords, but also the likelihood that two terms are given together and the centrality of terms to the overall network, per grouping. We did not attempt to harmonize or reduce duplication in keyword usage. Based on our assessment of the top cited papers, journals, and keyword content analysis, we have ascribed a two or three-word label for each group.

Only two of the groups (groups one and three) contained papers published prior to 2006 - two from 2005 in group one, and two from 1993 in group three. Indeed, most of the publications in each group were published just in the last five years (2011-2015). The 281 publications in the reduced dataset were published in 19 different journals. Energy Policy and Renewable and Sustainable Energy Reviews were the top two journals overall (154 and 42 publications, respectively), followed by the International Journal of Greenhouse Gas Control (24 publications) and Renewable Energy (16 publications). This 
breakdown remained somewhat consistent across the different groupings, though the International Journal of Greenhouse Gas Control was the top journal in group four (and completely absent from the other groupings). The International Journal of Hydrogen Energy was tied for first place in group seven.

There were 231 unique keywords used in group one (coloured pink). The top keywords (by frequency of use) were wind energy/power (there are separate terms for wind power and wind energy), attitudes, social acceptance and NIMBY. Wind power ranked first by betweenness centrality, followed by social acceptance and wind energy. The strongest connection in the co-occurrence network is between social acceptance and wind energy. There is some evidence of the importance of the Wüstenhagen et al 2007 article, in that 'social acceptance' shows connections with 'community acceptance', 'market acceptance', and 'socio-political acceptance'. We will refer to this group as the wind power / attitudes / NIMBY group.

The top keywords in group two (of 121 unique terms) were renewable energy, willingness-to-pay, social acceptance, contingent valuation and green electricity. However, the strongest connection in the cooccurrence network is between the two top ranked terms (based on centrality): willingness-to-pay and renewable energy. We will tentatively refer to this group as the willingness-to-pay/renewable energy group, and it is coloured blue. Group three (green) used 130 unique terms, the top by usage being energy conservation, climate change, bioenergy and behaviour change. Ranking by centrality was similar, with energy conservation ranked first, followed by climate change and behaviour change. Strong connections existed between climate change and energy, as well as among energy conservation, behaviour change, behavioural economics, energy consumption, psychology and household energy use. Group three will be labelled households / consumption / behaviour. 


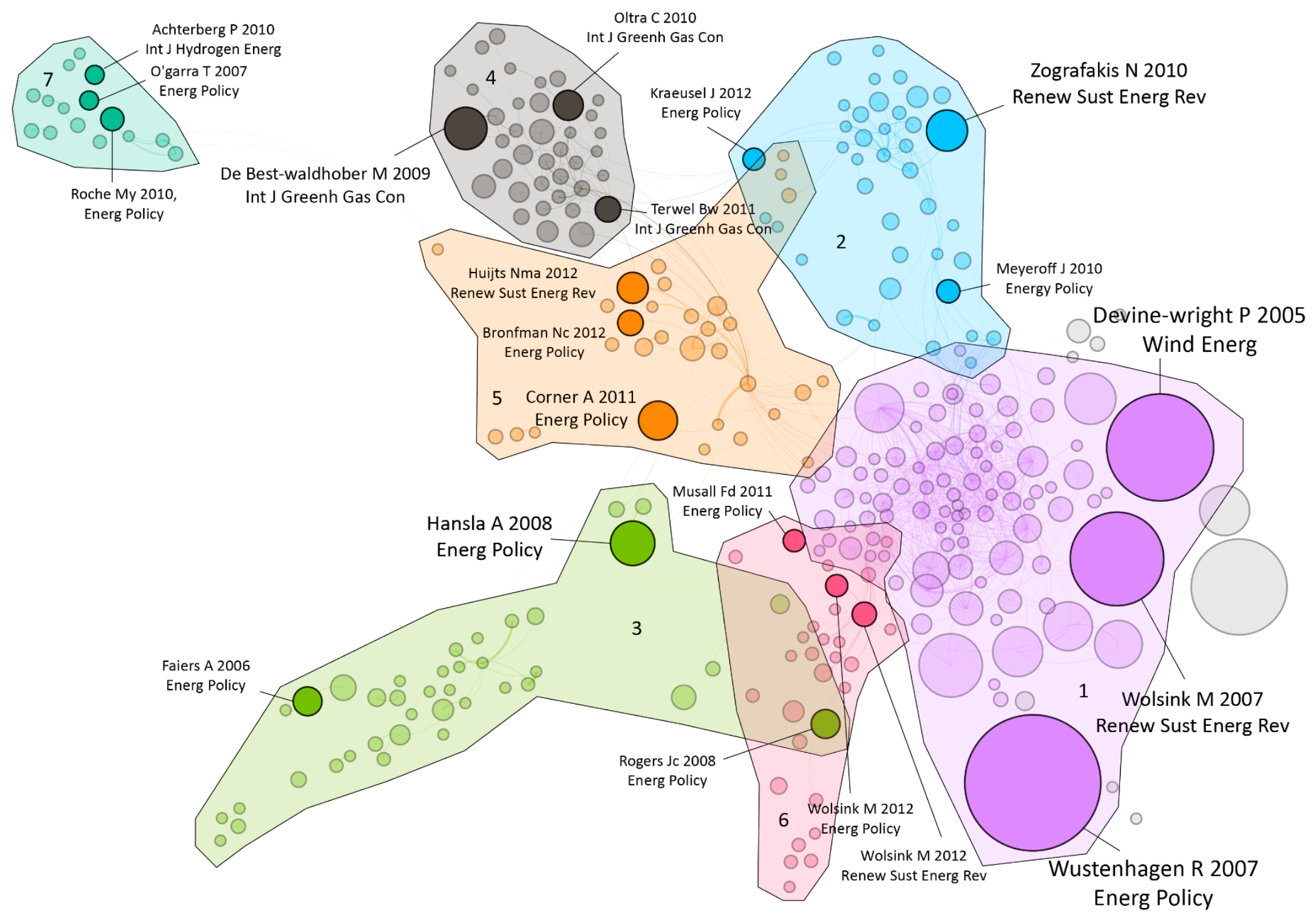

Figure 2) Social Acceptance Research Fronts - Node size based on citations 
Table 3) Social Acceptance Research Fronts, Summary Table

\begin{tabular}{|c|c|c|c|c|c|c|}
\hline Group & Name & Top 3 Keywords (by frequency) & $\begin{array}{l}\text { Top Journals } \\
\text { (by publications) }\end{array}$ & $\begin{array}{l}\text { Top Authors } \\
\text { (by \# of papers) }\end{array}$ & $\begin{array}{c}\text { Size } \\
\text { (\# of } \\
\text { papers) }\end{array}$ & $\begin{array}{c}\text { Age } \\
\text { (\% of } \\
\text { papers } \\
\text { 2011-2015) } \\
\end{array}$ \\
\hline ALL & $\mathrm{N} / \mathrm{A}$ & $\begin{array}{l}\text { Renewable energy; social } \\
\text { acceptance; wind energy }\end{array}$ & $\begin{array}{c}\text { Energy Policy (154); Renew. Sust. } \\
\text { Energ. Rev. (42) Int. J. Greenh. } \\
\text { Gas Control (24) }\end{array}$ & $\begin{array}{c}\text { Siegrist M; Wolsink M; Ashworth } \\
\text { P; }\end{array}$ & 281 & $79.4 \%$ \\
\hline 1 & $\begin{array}{l}\text { Wind power / } \\
\text { attitudes / NIMBY }\end{array}$ & $\begin{array}{l}\text { Wind energy; wind power; } \\
\text { attitudes }\end{array}$ & $\begin{array}{c}\text { Energy Policy (56); Renew. Sust. } \\
\text { Energ. Rev. (15); Renew. Energ } \\
\text { (7) }\end{array}$ & $\begin{array}{c}\text { Wolsink M (5); Devine-Wright P } \\
\text { (4); Eiser, Jr (4); }\end{array}$ & 90 & $69 \%$ \\
\hline 2 & $\begin{array}{l}\text { Willingness-to-pay / } \\
\text { renewable energy }\end{array}$ & $\begin{array}{l}\text { Renewable energy; willingness- } \\
\text { to-pay; social acceptance }\end{array}$ & $\begin{array}{c}\text { Energy Policy (17); Renew. Sust. } \\
\text { Energ. Rev. (10); Renew. Energ } \\
\text { (4) }\end{array}$ & $\begin{array}{c}\text { Tsargarakis KP (3); Claudy Mc (2); } \\
\text { Ladenburg J (2) }\end{array}$ & 39 & $85 \%$ \\
\hline 3 & $\begin{array}{l}\text { Households / } \\
\text { consumption / } \\
\text { behaviour }\end{array}$ & $\begin{array}{l}\text { Energy conservation; climate } \\
\text { change; bioenergy }\end{array}$ & $\begin{array}{l}\text { Energy Policy (25); Renew. Sust. } \\
\text { Energ. Rev. (4); Energy Effic. (3) }\end{array}$ & $\begin{array}{c}\text { Faiers A (3); Neame C (3); Upham } \\
\text { P (3); }\end{array}$ & 39 & $72 \%$ \\
\hline 4 & $\begin{array}{l}\text { Carbon capture and } \\
\text { storage / } \\
\text { communication / } \\
\text { perceptions }\end{array}$ & $\begin{array}{l}\text { CCS; Carbon capture and storage; } \\
\text { public perceptions }\end{array}$ & $\begin{array}{l}\text { Int. J. Greenhouse Gas Control } \\
\text { (24); Energy Policy (9) }\end{array}$ & $\begin{array}{c}\text { Siegrist M (6); Ashworth P (5); } \\
\text { Oltra C (5); }\end{array}$ & 38 & $90 \%$ \\
\hline 5 & Nuclear / risk / values & $\begin{array}{c}\text { Nuclear energy; nuclear power; } \\
\text { Fukushima }\end{array}$ & $\begin{array}{c}\text { Energy Policy (23); Renew. Sust. } \\
\text { Energ. Rev (4) }\end{array}$ & $\begin{array}{c}\text { Siegrist M (5); Hills P (3); Mah } \\
\text { Dny (3) }\end{array}$ & 31 & $97 \%$ \\
\hline 6 & $\begin{array}{c}\text { Communities / } \\
\text { renewable energy / } \\
\text { policy }\end{array}$ & $\begin{array}{l}\text { Renewable energy; Wind energy; } \\
\text { Community energy; }\end{array}$ & $\begin{array}{c}\text { Energy Policy (18); Renew. Sust. } \\
\text { Energ. Rev (6); }\end{array}$ & $\begin{array}{c}\text { Menichetti E (2); Stephens JC (2); } \\
\text { Taube Fa (2); }\end{array}$ & 29 & $86 \%$ \\
\hline 7 & Hydrogen / vehicles & $\begin{array}{l}\text { Public acceptance; Hydrogen } \\
\text { vehicles; Preferences }\end{array}$ & $\begin{array}{c}\text { Energy Policy (6); Int. J. Hydrog. } \\
\text { Energ (6) }\end{array}$ & $\begin{array}{c}\text { Achterberg P (2); Bayer, Sb (2); } \\
\text { Hao Y (2); }\end{array}$ & 15 & $73 \%$ \\
\hline
\end{tabular}


Of the 97 unique terms used in group four, CCS, carbon capture and storage, public perception, carbon capture and storage (ccs), and communication were top by usage. ${ }^{5}$ CCS and public perception were top by centrality, and the strongest connections existed between CCS, carbon capture and storage, and public perception. Interestingly, 'trust' ranks highly after the top six terms by centrality (four of which are variations on carbon capture and storage). Group four is labelled the carbon capture and storage / communication / perceptions group, and it is coloured grey in the network map. Group five (orange) used 80 unique keywords. The top by usage were nuclear energy, nuclear power, Fukushima, renewable energy and public acceptance. By centrality however, 'values' ranked first, followed by renewable energy, nuclear energy and nuclear power. The strongest co-occurrence occurs between nuclear energy and renewable energy, and among nuclear power, risk perception and Fukushima. Group five will be labelled the nuclear / risk / values group.

In group six (red), the top terms (of 103 unique terms) by usage were renewable energy, wind energy, community energy, and social acceptance. By centrality, the top three terms were renewable energy, community energy, and social acceptance. The strongest connection was between renewable energy and social acceptance. Without further investigation, this group appears to mirror the first. However, glancing over the keyword groupings that connect the three main terms, it appears this group is both less focused on wind energy and NIMBYism than group one, and perhaps more concerned with communities and the promotion of renewable energy in general. Therefore, we will refer to this group as the communities / renewable energy / policy group. Finally, group seven (blue-green) is the hydrogen / vehicles group. Of the 47 unique terms in this group, public acceptance, hydrogen vehicle, preferences, hydrogen, and hydrogen technology were the most commonly used. By centrality, public acceptance and hydrogen vehicle rank the highest, followed by government policy.

\subsubsection{Intellectual Bases}

The final step in the analysis of the citation network was to visualize the intellectual bases of each research front grouping. This was accomplished via co-citation analysis. The method used for each subdomain was to extract the paper citation network using Sci2, run the co-citation analysis, filter out connections between nodes less than or equal to one, run the MST pathfinder network pruning algorithm, delete isolates, run the Louvain community detection and betweenness centrality analyses, and export to Gephi for visualization (wherein node size is based on centrality). The resulting network graph is shown below in Figure 3, and a summary table shown in Table 4.

For each intellectual base, we looked at the ratio of articles cited outside our original dataset to those inside the original dataset (to get a sense of the extent to which research fronts draw on a wider body of literature), as well as the publication years (i.e., the age) of the articles cited in each grouping. We also looked at the range and number of journals cited by each group. In general, the intellectual bases for the literature are comprised of roughly $80 \%$ articles outside the original dataset and $20 \%$ within, and typically $80 \%$ or more of the intellectual base is comprised of articles published in the past 15 years. There is some variation in both statistics across groupings, however. Analysis of the co-citation record of each front indicated that groups three, five, and seven (households / consumption / behaviour, nuclear / risks / values, hydrogen / vehicles) possessed older 'intellectual bases' than the other groups.

\footnotetext{
${ }^{5}$ It seems obvious that CCS, carbon capture and storage, and carbon capture and storage (ccs) are all referring to the same thing, but in the interest of not manipulating the data based on our assumptions of authors' intentions, we left all terms exactly as they appeared in the dataset.
} 
These groups were also the least 'self-referential' (that is, the proportion of top articles cited from outside the original dataset was higher for these groups) (see the columns 'Extent' and 'Age' in Table 3).

The reliance on literature outside our original dataset in groups three, five and seven may in part be due to citation practices characteristic of different disciplinary backgrounds. In both groups three and five, the Journal of Environmental Psychology and Environmental Behaviour journals ranked among the top four cited journals. The Risk Analysis journal ranked highly in groups four and five, suggesting a connection between social acceptance and technological risk perception in literature with a psychology background. Planning journals ranked more highly in the first group than the others (the Journal of Environmental Planning and Management placing $4^{\text {th }}$, Land Use Policy at $5^{\text {th }}$, the Journal of Environmental Policy \& Planning at $13^{\text {th }}$ and Environmental Planning $A$ at $18^{\text {th }}$ ), perhaps owing the importance of wind turbine siting concerns in association with NIMBYism. Lastly, the willingness to pay / renewable energy group is a heavily economics-based research front, with an intellectual base publishing in Ecological Economics (ranked $3^{\text {rd }}$ ), Energy Economics $\left(5^{\text {th }}\right)$, the Journal of Environmental Economics \& Management $\left(6^{\text {th }}\right)$, and the Environmental Resource Economics $\left(7^{\text {th }}\right)$ journals.

Looking at the structure of the citation networks, we can make some brief observations on the diversity of the intellectual base and some of key characteristics of current research fronts. Group 1 (wind power / attitudes / NIMBY) is divided into seven main communities, the four largest being centred around papers by D. Bell, M. Wolsink, and P. Devine-Wright $[4,7,31,34]$. The focus of all of these papers is squarely on wind power, and in particular on NIMBYism as an primary factor underlying the "social gap" between positive general public opinion and negative personal perspectives on specific renewable energy projects and thus some attention is given to siting and/or proximity (i.e., spatial considerations) as an important variable [6]. Explaining the social gap in a way that doesn't resort to simplistic accounts of self-interest, focusing on factors such as community ownership, sense of place, trust in the process and perceived fairness [35-38], is perhaps the defining characteristic of this grouping.

The second group (willingness to pay / renewable energy) was broken up into seven groups as well, again with four prominent communities. As noted above, this literature is the most economics-oriented of the intellectual bases, though with some connections made to the psychology-based literature found in group three $[39,40]$. The defining characteristic of this base is the interest in assessing differential levels of 'willingness to pay' (WTP) amongst consumers (typically in the residential electricity sector) for different green or renewable energy technologies [41,42]. This literature base appears to present two main methodologies for assessing WTP: the choice experiment method $[41,42]$ and the contingent valuation method $[43,44]$, both of which seek to derive economic values for non-economic benefits, the former by inferring those values from choices people make, the latter by asking people to state those values.

The link between values and behaviour is the domain of the third group, labelled here households / consumption / behaviour. This group contains eight prominent communities, all centred around Stern 2000, providing a conceptual framework for explaining "environmentally significant" behaviour [45]. The framework combines insights from the value-beliefs-norms theory (VBN) of environmentalism with the 'ABC theory' of behaviour (i.e., behaviour (B) depends on attitudes (A) and context (C)), highlighting four main causal variables - attitudinal factors, contextual factors, personal capabilities and habits/routines [45]. There are three main 'flanks' of literature connected to Stern 2000 . The left flank tends to be older empirical studies of the connections between homeowner attitudes and energy 


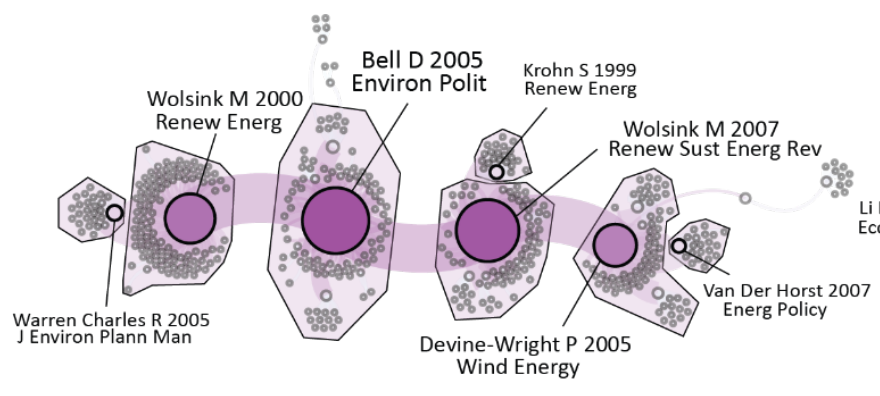

GROUP 1: WIND POWER / ATTITUDES / NIMBY

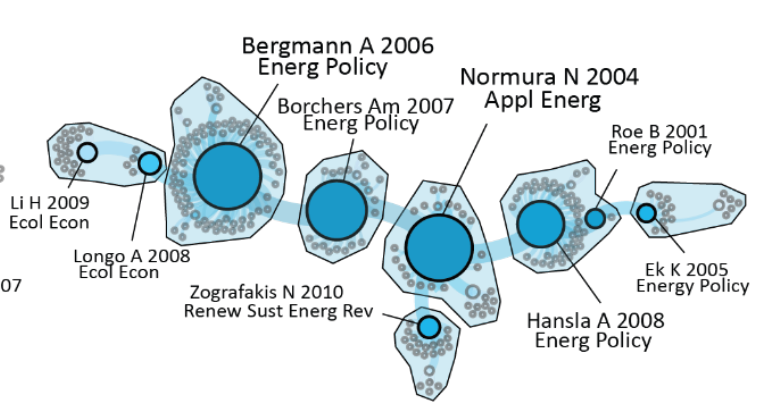

GROUP 2: WILLINGNESS-TO-PAY / RENEWABLE ENERGY
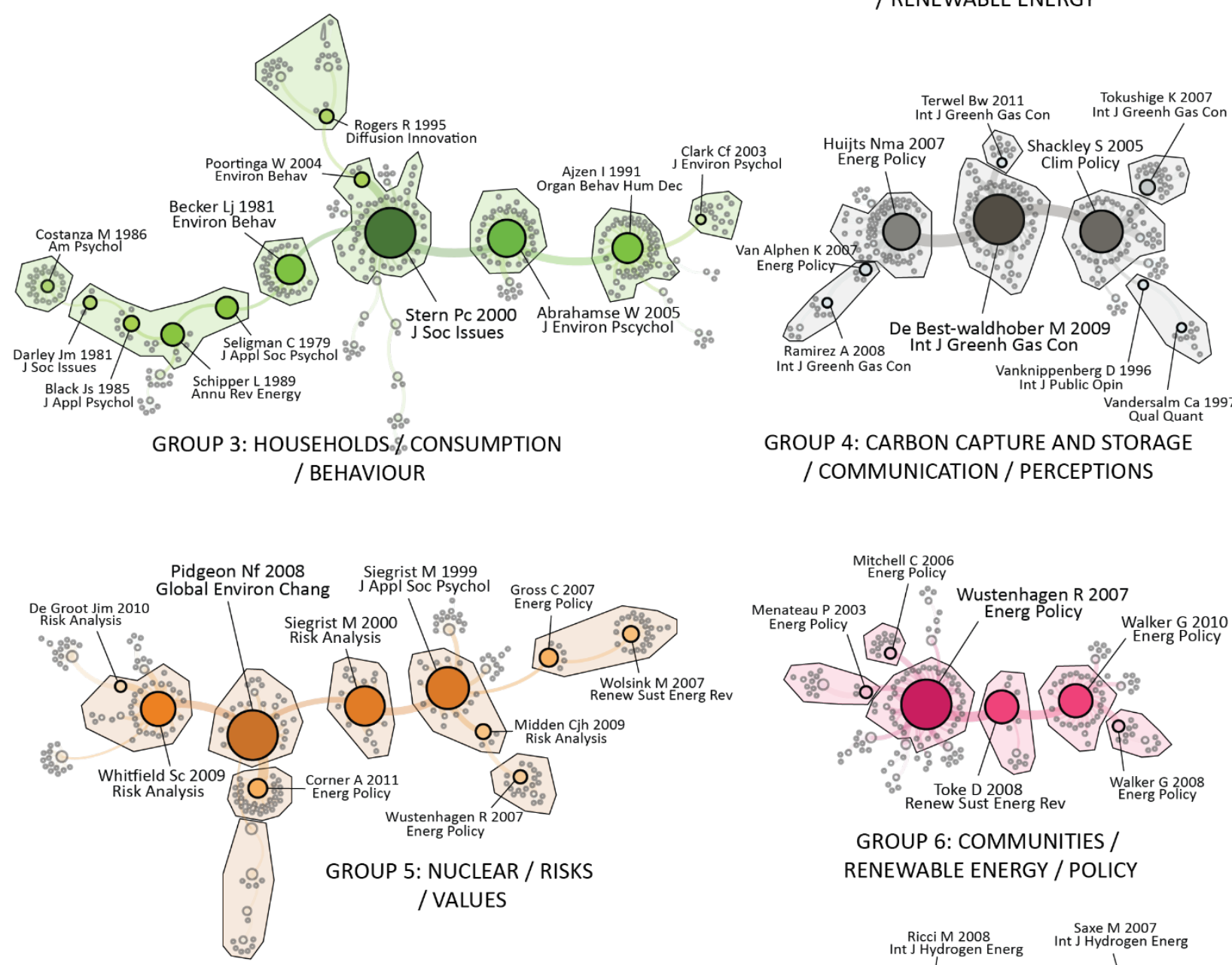

GROUP 6: COMMUNITIES / RENEWABLE ENERGY / POLICY

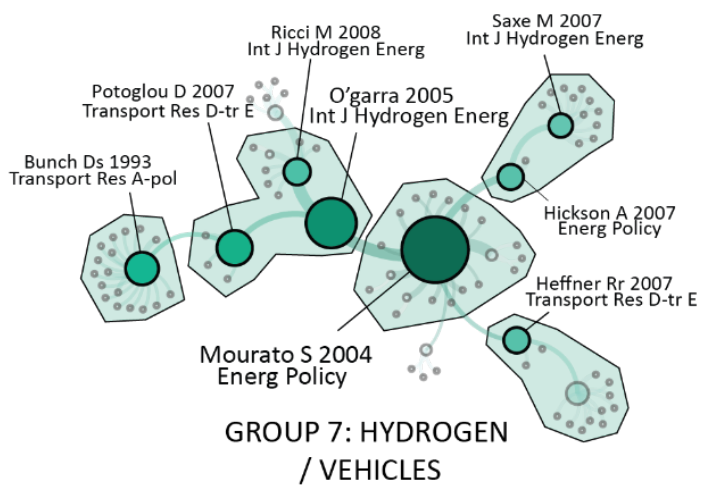

Figure 3) Intellectual Bases for Social Acceptance Research Fronts 
Table 4) Summary of Intellectual Bases

\begin{tabular}{|c|c|c|c|c|c|c|c|c|c|c|}
\hline \multirow[b]{2}{*}{ Group } & \multirow{2}{*}{$\begin{array}{c}\text { Size } \\
\text { (\# of Cited } \\
\text { References } \\
\text { ) }\end{array}$} & \multirow{2}{*}{$\begin{array}{c}\text { Size } \\
\text { (\# of Top } \\
\text { Papers) }\end{array}$} & \multirow{2}{*}{$\begin{array}{c}\text { Extent } \\
\text { (\% of Top } \\
\text { Outside) }\end{array}$} & \multirow{2}{*}{$\begin{array}{c}\text { Age } \\
\text { (Median } \\
\text { Year of } \\
\text { Top } \\
\text { Papers) } \\
\end{array}$} & \multirow[b]{2}{*}{$\begin{array}{l}\text { Top } 3 \text { Papers } \\
\text { (Centrality) }\end{array}$} & \multicolumn{5}{|c|}{ Journals } \\
\hline & & & & & & $\begin{array}{c}\text { \# of } \\
\text { Publica } \\
\text { tions }\end{array}$ & $\begin{array}{c}\text { \# of } \\
\text { Journals }\end{array}$ & Top 4 Journals & $\begin{array}{c}\text { \# of } \\
\text { Articles }\end{array}$ & Share \\
\hline \multirow{4}{*}{$\begin{array}{l}\text { wind power / } \\
\text { attitudes / nimby }\end{array}$} & \multirow{4}{*}{434} & \multirow{4}{*}{17} & \multirow{4}{*}{$52 \%$} & \multirow{4}{*}{2005} & \multirow{4}{*}{$\begin{array}{l}\text { Bell D, 2005; } \\
\text { Wolsink M 2007; } \\
\text { Wosink M 2000; }\end{array}$} & \multirow{4}{*}{217} & \multirow{4}{*}{100} & Energ Policy & 96 & $33.4 \%$ \\
\hline & & & & & & & & Renew Sust Energ Rev & 19 & $6.6 \%$ \\
\hline & & & & & & & & Renew Energ & 12 & $4.2 \%$ \\
\hline & & & & & & & & J Environ Plann Man & 10 & $3.5 \%$ \\
\hline \multirow{4}{*}{$\begin{array}{l}\text { willingness to pay / } \\
\text { renewable energy }\end{array}$} & \multirow{4}{*}{235} & \multirow{4}{*}{12} & \multirow{4}{*}{$63 \%$} & \multirow{4}{*}{$2006 / 7$} & \multirow{4}{*}{$\begin{array}{c}\text { Bergmann A 2006; } \\
\text { Nomura N 2004; } \\
\text { Borchers Am 2007 }\end{array}$} & \multirow{4}{*}{100} & \multirow{4}{*}{61} & Energ Policy & 61 & $31.9 \%$ \\
\hline & & & & & & & & Renew Sust Energ Rev & 18 & $9.4 \%$ \\
\hline & & & & & & & & Ecol Econ & 12 & $6.3 \%$ \\
\hline & & & & & & & & Renew Energ & 11 & $5.8 \%$ \\
\hline \multirow{4}{*}{$\begin{array}{l}\text { households / } \\
\text { consumption / } \\
\text { behaviour }\end{array}$} & \multirow{4}{*}{298} & \multirow{4}{*}{42} & \multirow{4}{*}{$87.5 \%$} & \multirow{4}{*}{2001} & \multirow{4}{*}{$\begin{array}{c}\text { Stern Pc 2000; } \\
\text { Abrahamse W } \\
\text { 2005; Ajzen I } 1991\end{array}$} & & & Energ Policy & 43 & $18.5 \%$ \\
\hline & & & & & & 114 & 96 & Environ Behav & 16 & $6.9 \%$ \\
\hline & & & & & & 117 & Ju & J Environ Psychol & 13 & $5.6 \%$ \\
\hline & & & & & & & & J Econ Psychol & 9 & $3.9 \%$ \\
\hline & & & & & De Best-waldhober & & & Int J Greenh Gas Con & 30 & $22.4 \%$ \\
\hline carbon capture and & 229 & 21 & $66 \%$ & 2009 & M 2009; Shackley S & 113 & 41 & Enrgy Proced & 26 & $19.4 \%$ \\
\hline communication & & $2 \pm$ & (20) & & 2005; Huijts Nma & ك+s & 71 & Energ Policy & 19 & $14.2 \%$ \\
\hline & & & & & & & & Risk Anal & 8 & $6.0 \%$ \\
\hline & & & & & & & & Energ Policy & 37 & $19.9 \%$ \\
\hline nuclear / risks / & 242 & 30 & $79 \%$ & $2005 / 6$ & Pidgeon Nf 2008; & 124 & 78 & Risk Anal & 32 & $17.2 \%$ \\
\hline values & 272 & Jo & 80 & 200070 & Siegrist M 2000; & 164 & & Environ Behav & 8 & $4.3 \%$ \\
\hline & & & & & & & & J Environ Psychol & 7 & $3.8 \%$ \\
\hline & & & & & & & & Energ Policy & 79 & $55.2 \%$ \\
\hline Communities / & 171 & 20 & $70 \%$ & 2007 & Wustenhagen R & $66-1$ & 10 & Res Policy & 8 & $5.6 \%$ \\
\hline policy & $1 / 1$ & 20 & $14 \%$ & 2007 & 2010; Toke D 2008; & 00 & 40 & Renew Sust Energ Rev & 8 & $5.6 \%$ \\
\hline & & & & & & & & Renew Energ & 5 & $3.5 \%$ \\
\hline & & & & & Mourato S 2004 : & & & Energ Policy & 15 & $23.4 \%$ \\
\hline hydrogen / vehicles & 89 & 12 & $80 \%$ & 2006 & O'garra T 2005; & 44 & 24 & Int J Hydrogen Energ & 13 & $20.3 \%$ \\
\hline & & & & & Potoglou D 2007 & & & Transport Res A-pol & 4 & $6.3 \%$ \\
\hline & & & & & & & & Transport Res A-pol & 3 & $4.7 \%$ \\
\hline
\end{tabular}

\footnotetext{
${ }^{6}$ Top papers are defined here as those with a betweenness centrality score greater than zero.
} 
consumption patterns (e.g., conservation during summer and/or winter [46,47]). The top flank connects the innovation diffusion literature [48] by way of a study of values and the adoption of energy saving technologies in households [49]. The right flank appears more theoretically-inclined, linking Stern's framework to Ajzen's theory of planned behaviour through Abrahamse et al's 2005 comprehensive review of the effect of antecedent and consequence interventions on energy-use behaviour [50,51].

The primary focus of the carbon capture and storage / communication group appears to be the formation of attitudes around a technology with which few are familiar. The important consideration, accordingly, lies in how (and from whom) information about the technology reaches the public, i.e., a communications consideration $[52,53]$. Here we find three primary groupings, centred on de BestWaldhober et al's 2009 use of an information-choice questionnaire [54,55] to study the formation of stable opinions on CCS among the general public [56]. Other important considerations appear to be the perceptions of risk around the technology [57], as well as perceptions of trust in key stakeholders or information providers $[58,59]$.

The perception of technological risk and its connection with attitudes towards energy technology is taken up by Group 5 as well, labelled here the nuclear / risks / values group. Pidgeon et al's research into the effects of reframing nuclear power in the context of climate change on public opinions of the technology in the UK is the most central study, in which the authors note that though the public does appear to "reluctantly accept" nuclear power as a potential climate change solution, "very few" prefer this option over other renewable options [60]. Whitfield et al look at perceptions of risk and attitudes toward nuclear power, but with a focus on the role of values, beliefs and trust in governance, echoing the environmental behaviour approach of Group 3 [61]. The two papers by Siegrist look at perceptions and attitudes toward 'gene technology', also highlighting the importance of trust $[62,63]$, and the paper by Midden and Huijts, bridging Siegrist's work to Wüstenhagen et al's 2007 article, looks at trust and risk perceptions around CCS [64].

The focus of the intellectual base for group six, the communities / renewable energy / policy group is similar to that of group one, except in that it is more general in its technological focus, is not intensely focused on NIMBYism, and instead is often more concerned with how meso-level policy and/or institutional factors can affect the deployment of renewable energy $[30,65,66]$. Indeed, prompting and/or managing a transition to a future, lower-carbon energy system appears to be a strong theme in this base [67-69]. That the Wüstenhagen et al 2007 introductory article is the most central to the base is perhaps not surprising, giving this front's more general research interests than those of groups one, four, or five.

Lastly, Mourato, Saynor and Hart's study of driver preferences for fuel cell vehicles in London is the core of the intellectual base for the hydrogen / vehicles group, in which the authors use the contingent valuation method to estimate taxi drivers' willingness-to-pay to participate in a hydrogen vehicle pilot program [70]. Other studies look at attitudes toward hydrogen as fuel in general [71,72], fuel-cell buses $[73,74]$, hybrid and/or 'clean' vehicles [75-77]. Therefore, the intellectual base for this front might be of broader interest to the transportation or 'fuels' sectors in general.

\subsection{Collaboration and Interdisciplinary Dialogue}

The final set of results pertain to the extent of collaboration and dialogue between authors and research fronts. To investigate this, we analyzed co-author (i.e., times that authors were listed together on a 
paper) and author-journal (i.e., times that authors published in specific journals) networks in the original dataset, as well as author-research front (number of research fronts each author had published in) and research front-journal (journal representation by research front) directed networks in the 281 top articles used to conduct the research front and intellectual bases analysis above.

Of the 2008 unique authors in our original dataset, 285 (14.2\%) on two or more papers and 93 (4.6\%) were listed on three or more papers. Taking the network as a whole, author collaboration patterns produced 556 distinct clusters (groups of connected authors), though the median size of these clusters was very small, at three researchers. The largest cluster contained 188 members $(9.4 \%$ of the 2008 total unique authors), while the second largest cluster contained only 28 members (1.4\%). Filtering by authors listed on two or more papers (this removes instances of papers with many authors, which inflates the degree ranking of each author), left 104 distinct collaboration clusters with a median size of two (the largest cluster contained 56 researchers). The five highest ranked authors by degree (number of authors collaborated with) were D. Reiner, P. Ashworth, S. Brunsting, P. Upham and E. Einsiedel - all of whom were included in the largest collaboration cluster. Within the next four largest clusters (having $10,8,6$, and 6 members respectively), the top authors ranked by degree were $C$. Wang (6); M. Siegrist (7); H. Boudet/C. Clarke (5); and M. Wolsink/R. Wüstenhagen (3). The most frequent collaborators were M. Siegrist and Vhm. Visschers, who co-authored five works together, followed by M. Siegrist/S. Dohle, Ddl. Daamen/Bw. Terwel, N. Zografakis/Kp. Tsagarakis, N. Pidgeon/W. Poortinga, N.Pidgeon/C. Demski and $\mathrm{Cr}$. Jones/Jr. Eiser, all with four collaborations (only Daamen/Terwel were members of the largest collaboration cluster). The vast majority ( $95 \%)$ of the remaining authors worked together once. Overall, roughly half of authors listed on two or more papers collaborated with two or more different authors, approximately a third with three or more authors, and about $11 \%$ with five or more unique authors.

Looking at author - journal network we find that of the 2008 unique authors, only $162(\sim 20 \%)$ were listed on publications in more than one journal. The highest number of journals published in was six (J. Ladenburg). The next most widely published authors were P. Upham (4) and P. Pelkonen (4) followed by 26 more authors listed on publications in three different journals. Looking only at first authors, the most widely published authors were J. Ladenburg (5) and P. Upham (4), followed by Am. Dowd, Nma. Huits, A. Kontogianna, M. Wolsink and Zh. Wang at 3.

Turning to the author-research front network (see Figure 4), we find limited evidence of inter-research group collaboration. A total of 843 unique authors were contained in the short list of 281 articles that were used to produce the research fronts/intellectual bases. Of these, only 39 authors had published in more than one research front, and only three authors in more than two research fronts (P. Upham, P. Ashworth and M. Siegrist were each listed across three research fronts). The greatest amount of collaboration (measured by number of authors cross-listed) was between the wind power / attitudes / NIMBY and willingness-to-pay / renewable energy groups.

Finally, looking at the research front - journal network (see Figure 5), we find that Renewable and Sustainable Energy Reviews and Energy Policy are the most common journals across all the research fronts, both of which were present in all seven groups. Renewable Energy, and Energies were tied for second, being present in five research fronts, and Applied Energy was third with four fronts. In the other direction, the willingness-to-pay and households-consumption-behaviour fronts published in the widest range of journals (nine each), followed by carbon capture and storage / communication / perceptions, 
which had published in seven journals. The rest of the fronts were more concentrated in a smaller range of journals, though each front (with the exception of the hydrogen / vehicles front) had their own 'front-specific' journals that no other front published in.



Figure 4) Authors - Research Front Network 


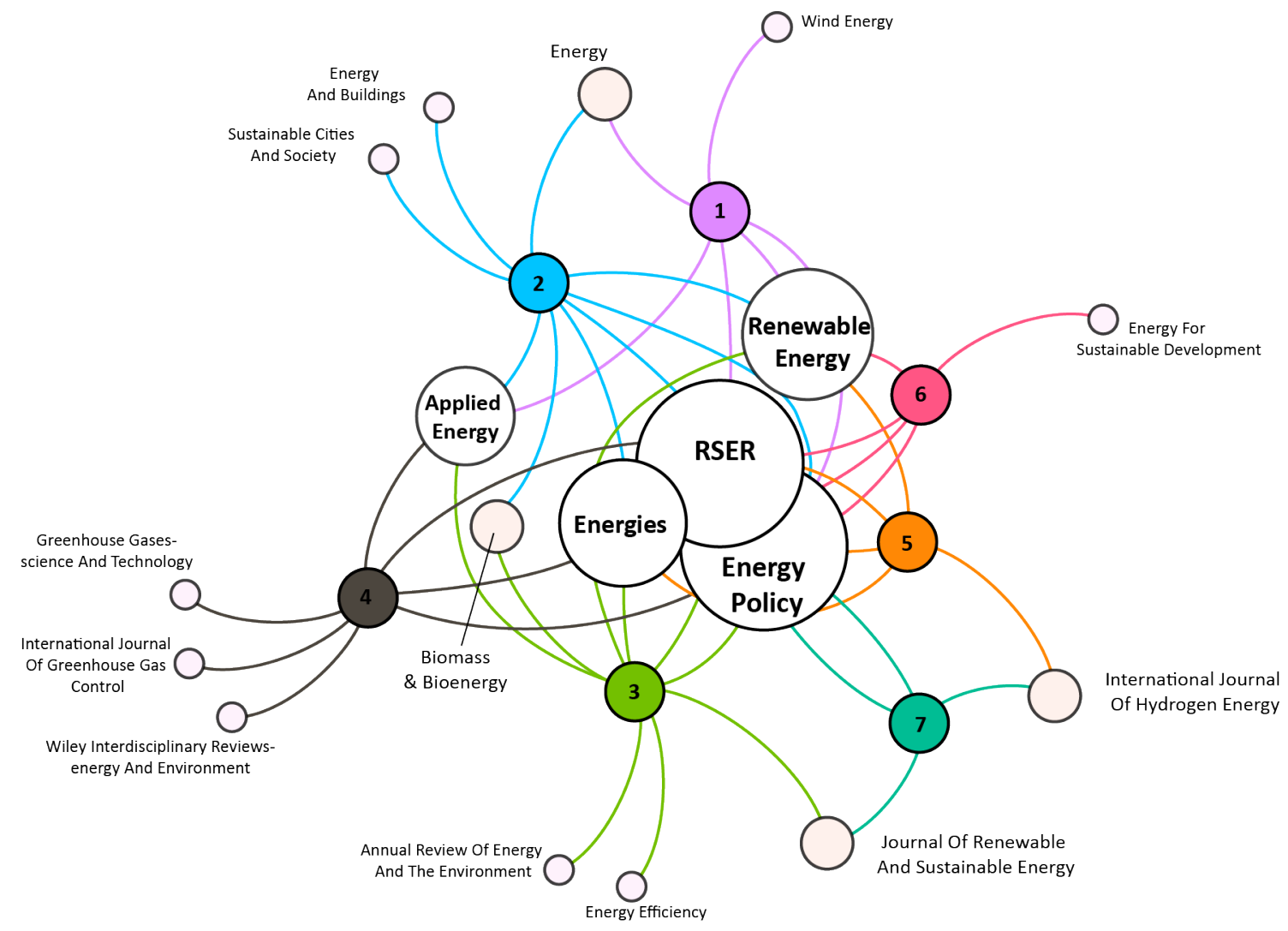

Figure 5) Research Front - Journal Network

\section{Discussion}

Having conducted our three separate analyses of the knowledge domain for the social scientific study of the social acceptance of energy and fuels, we can make several observations as to trends and characteristics of influence within the field, the underlying structure of the field and its correspondence with the aforementioned community / market / socio-political acceptance schema, and the extent of collaboration and interdisciplinary dialogue and shaping the direction of research in the field.

\subsection{Influence}

The results of the basic characteristics analysis indicate that the geographic balance of influence in the literature has shifted progressively toward publications in the 'rest of the world' category, and away from its historic centre in the US and the UK. With that being said, it should be noted that of the top 16 countries that account for $80 \%$ of all publications in our dataset, only two were non-Western (China, at $8^{\text {th }}$, and Japan, at $16^{\text {th }}$ ). This raises some concern over the applicability of findings in this literature to lower-income countries, countries with weaker regulatory and/or planning and assessment processes, or countries with less democratic political institutions in general (concerns raised by Devine-Wright over 10 years ago) [4].

Energy Policy is by far the most influential journal across this field, ranking in the top two or three journals among six of seven research fronts and their respective intellectual bases, followed by Renewable and Sustainable Energy Reviews, ranking among the top in five of seven research fronts and two of seven intellectual bases (both journals are represented in all seven research fronts, however, as 
found in the research front-journal analysis). Our initial keyword analysis suggests that, broadly speaking, the field is focused on renewable energy, though from an energy source/technology standpoint wind power looms the largest (in terms of keyword frequency).

Looking at the citation networks within our dataset, the initial impression is that group one (wind power / attitudes / NIMBY) is indeed the most influential, and perhaps the literature that is most often called to mind when discussing the social acceptance of energy and fuels (for example, the highest cited articles across our dataset were found in this grouping ([14],[4],[33]). Group one is also the largest of all the research fronts (in terms of numbers of publications), and the proximity of groups two, three, five and six to group one on the network map suggest that each of the former groupings draws heavily on the literature contained in the latter. Group one had the lowest share of papers published in the past five years, however, suggesting both that it is the oldest of the research fronts examined here and, therefore, that research interests may be shifting elsewhere.

It should be noted that though the papers by Wüstenhagen et al., Devine-Wright, and Wolsink were highly cited, they are nevertheless all on the "outskirts" of the network map. When comparing the map with node size based on citations versus the map with node size based on centrality (see Appendix A) it becomes apparent that group one is not as central to current research across the field as perhaps it once was. Indeed, group five's general central positioning in the map suggests that future scholars may be influenced more by research outside the wind power / attitudes / NIMBY group than within it. If that is indeed the case, the relative influence of certain authors and their approach to the problem of social acceptance within the field may shift as well. For example, the work by researchers like Bell, Wolsink and Devine-Wright on NIMBYism and wind power may have been highly influential in terms of focusing the concerns of the Group 1 research front, and for conceptualizing the problem of social acceptance as (generally speaking) a problem of governance, but as the centre of influence shifts toward groups three and five so too might the conceptualization of acceptance move toward the perspectives of Ashworth, Siegrist, Upham, Huijts and other scholars looking at values, beliefs, and perceptions of technological risk. Indeed, the figure showing the author-research front collaboration indicates that three of these scholars, none of whom are traditionally associated with the wind power / attitudes / NIMBY front, may be most 'influential' in the literature now, given their representation in three separate research fronts.

Overall, we can observe a broad shift in influence from social acceptance as a political issue to social acceptance as a psychological issue. Turning back to the map based on centrality, we can observe that papers with higher centrality tend to be more recent than highly cited publications and that the top papers tend to bridge Group 5 with different research fronts (again supported by the prominent role of Ashworth and Siegrist in Figure 4. The highest ranked paper here is Perlaviciute and Steg's 2014 paper published in Renewable and Sustainable Energy Reviews, wherein the authors provide what they believe to be the first general framework in the literature to bring together contextual factors (i.e., factors more commonly found in the literature from group one) with psychological factors (i.e., those found in groups three, four and five) affecting general public and community acceptance of energy "alternatives" [13]. (They conclude with a series of policy suggestions for promoting sustainable energy transitions, thereby connecting with literature from group six as well). This effort is similar to other recent framework papers [12] and is largely in line with the call for greater interdisciplinary dialogue dating back to DevineWright's highly-cited framework paper from 2005 [4]. 
All of this suggests that the centre of influence across the field is shifting from its original location in group one (i.e., planning, sociology) to a more interdisciplinary combination of environmental psychology, economics and 'contextual' analysis, characteristic of recent work found in groups three and five. Important bridges are being built between groups three and six [78], three and five [79], five and seven [80] and two and five [81]. The predominant subject matter appears to be moving away from renewable energy in general and wind power in particular, to a broader concern with any or all energy technologies that would or could be part of a transition to a lower-carbon energy future (e.g., CCS, nuclear, and alternative technology in the transportation sector).

\subsection{Structure}

By many measures, the paper by Wüstenhagen et al., [14] was and remains one of the most influential frameworks for conceptualizing social acceptance across the field. Not only was this paper the highest cited in our dataset and in the 281 articles comprising the seven research fronts, it also figured prominently in four intellectual bases as well - the only paper common across that many bases (see Section 5.3 below). Indeed, based on their review of the literature, Upham et al., found fit to agree with Wüstenhagen et al.'s three "typical" levels of acceptance analysis (though breaking out the level and object of analysis, as noted above) [3]. However, we do not find much support for the original community / market / socio-political distinction as an orienting framework for the conceptualization of social acceptance at present (though Upham et al's revised version is much more representative of the diversity of the field.)

Our analysis suggests that current research is grouped more by technology and intellectual heritage than by the kind of acceptance in question. With the exceptions of groups two and three (and perhaps six) the research fronts were all focused to a greater or lesser degree on one specific energy technology or fuel (i.e., wind in group one, CCS in group four, nuclear in group five, and hydrogen in group seven). Moreover, as will be discussed further in Section 5.3, the intellectual bases for these fields are highly distinct, with very little overlap. Thus, we find the groupings to be relatively tightly clustered (particularly groups one, four, and seven) with little overlap and few bridges in between. It is important to recall that these groups are defined by the citation practices of researchers working in these areas. Accordingly, what this suggests is that the 'dialogue' taking place in each grouping is less focused on explaining 'community acceptance' (with the exception of groups one and six) or 'market acceptance' per se, and more oriented around particular issues of acceptance that outside observers interpret as being most relevant to communities or markets (i.e., trust and perceptions of fairness, willingness to pay).

Moreover, these differences often appear to parallel methodological approaches of the researchers, which stem in large degree from their respective disciplinary backgrounds. Contingent valuation methods, for example, were very prevalent in group two, but rarely found elsewhere (though this may be changing). Similarly, informed choice questionnaires tended to be found in group four. The ValuesBeliefs-Norms theory and the Theory of Planned Intention (i.e., the psychology-influenced perspectives) were found across groups three and five in particular, but also to a lesser extent in group two, and place-based and siting concerns, visibility and aesthetics, the importance of trust and fairness are all concerns that are found predominately in group one. Accordingly, we find some support for Upham et al's perspectives on acceptance, categorized by disciplinary background, i.e., economics (group two), sociology and human geography (groups one and six), social psychology (groups three, four and five). 
We do not observe distinct research fronts for the a 'cultural theory' approach, though one could argue that the prominence of research methodology and theoretical frameworks in groups two and four also fit under 'frameworks and methods driven work', as described by Upham.

Group seven is interesting in that it is very technology focused (hydrogen), but also the only group that is looking at the transport sector of energy systems (hybrid vehicles, public transport). Here we find use of concepts common in group two (willingness-to-pay), and some bridges being built with group five (risk perceptions) as well (on the basis of citation similarity). Within the author-research front network, we also find that some researchers within group seven have published in groups two, three and four. This suggests that the perspective on acceptance in this group derives more from the attributes of the technology that are generalizable across research groups, rather than from a familiar theoretical / methodological toolset that is being brought to bear on the question at hand.

Nevertheless, the close connection between technology and intellectual heritage in defining other research fronts raises some concerns about generalizing findings about acceptance across the field. If it is the case that the problem of acceptance is unique to different technologies, actor groups or energy system sectors, then what hope is there for interdisciplinary efforts to integrate different theoretical or methodological approaches to the topic into one framework? Conversely, does too much focus on generalizable technological attributes or psychological processes risk divorcing the problem of acceptance from the larger, socio-technical context of transitioning to a more sustainable energy system? In short, to what extent can (or should) efforts to integrate findings in wholistic frameworks produce a comprehensive, holistic theory of social acceptance versus just catalogue differences?

\subsection{Interdisciplinary Dialogue}

The call for greater theoretical and methodological sophistication, to be achieved in part through interdisciplinary dialogue, dates back to Devine-Wright's 2005 review paper on public perceptions of wind power noted above [4]. Yet the challenge of producing consistent knowledge in a field characterized by great theoretical and methodological diversity continues to 'vex' the field, as Upham et al., note in their conclusion: "each design and method produces a particular type of knowledge, framed in a particular way, with a different purpose, scope, limitations and conditionality" [3]. The latter's answer to the question posed above about interdisciplinary frameworks is to note the value in establishing common ground between incommensurable perspectives, despite some loss of "theoretical integrity", in order to support "interactive pluralism" and greater dialogue between perspectives. Do we find this in this knowledge domain?

Our analysis of intellectual bases indicates that there are some well-defined disciplinary borders that separate and define ongoing work on social acceptance of energy and fuels. There were few instances in which influential papers in one intellectual base were also influential in another. In fact, out of the 198 'top' papers across the intellectual bases, only 11 were central to more than one base, and only two found in more than two bases [14 (groups one, two, five and six), 32 (groups one, two, and five)]. Moreover, the differences in top journals across the intellectual bases also indicates some disciplinary silos underpinning current work in each front. All of this suggests that, at least in the earlier literature found in each research front, there was little dialogue across research groups and few interdisciplinary studies. However, our analysis of research fronts suggests that this may be changing. 
When we look at the research front map based on centrality, for instance, we find that many top papers combine theoretical frameworks and methodologies from multiple different research fronts. For instance, the paper by Bidwell in group one uses structural equation modeling to test the relationship between values/beliefs/norms (i.e., the VBN framework developed by Stern, in the group three intellectual base) and attitudes toward wind energy in Michigan [82]. Also in group one, Kontogianni et al., use probabilistic multivariate modelling to assess determinants of community acceptance of wind power in Greece, a methodology (they believe) that had only once before been applied to the topic of social acceptance [83]. Carlisle et al's unique contribution, on the other hand, appears to be a novel subject matter (utility scale solar) for which they find few previous studies [84]. We find similar evidence of cross-fertilization in group two, where the two most central papers both draw upon the Theory of Planned Behaviour to inform their analysis of willingness-to-pay for renewable energy in Shandong, China [85], and for CCS in Dresden, Germany [86]. In both studies, the authors bring to bear research techniques on a topic that (according to the authors) had not yet been studied in that manner (rural residents' perceptions in China, willingess to pay for CCS in Germany). In group three, we find that two of the three most central papers link the research front to other communities. Both of these papers address themselves to a perceived lack of scientific (i.e., theoretical) rigour in investigations of renewable energy acceptance. Poortinga et al., use an adapted version of Stern's VBN framework to investigate acceptability of both demand and supply-side strategies to reduce carbon emissions, noting that previous work on supply-side project siting has been "a-theoretical" [79]. Similarly, Upham associates research on project siting (i.e., group one) with an interpretivist epistemology that disregards falsifiable propositions in favour of building understanding of how people construct meaning, and suggests that the more explanatory approach of environmental psychology (group three) has much to offer [78]. Both papers are thus indicative of increased interdisciplinary activity, and the desire to bring together the contextual with psychological explanations of acceptance, as expressed by Perlavicuite et al [13].

Results for the co-author analysis indicates that inter-researcher collaboration is concentrated in relatively small networks of two or three people, and that most researchers collaborated with only one or two others. Conversely, few researchers consistently co-author multiple papers together, and most of these authors are in smaller research clusters. Overall, this suggests that researchers tend to collaborate with small networks of well-known associates (excluding collaboration with authors listed on only one paper, many of whom may be students of the more prolific collaborators). The authorresearch network indicates that most of this collaboration is likely taking place within research fronts, rather than between them, suggesting low intensity inter-topic dialogue, but not necessarily absence thereof. Instead, we find that all researcher fronts are connected to three or more other research fronts, typically through authors that are both prolific publishers and collaborators (e.g., M. Siegrist, P. Ashworth, and P. Upham). The research front with the fewest direct connections to other research fronts was, somewhat surprisingly, the nuclear / risk / values front, the centrality analysis for which, as discussed above, indicated as being an emerging 'core' in the literature. Here it is important to recall the research front network was created on the basis of bibliographic coupling (i.e., similar citation patterns) while the author-research front network shows connections from authors to the research fronts they published in. Accordingly, the lower level of connections with other research fronts shown for group five in Figure 4 coupled with the high centrality of that group in Appendix A suggests that researchers in that group are drawing from or building upon a wider range of literature than are researchers in other fields, but conducting research on a narrower range of topics. Therefore, group 
five may in fact be the most 'interdisciplinary' (in the sense that it is integrating findings from other fronts), even if it is not collaborating with researchers in many other fronts.

It thus appears that Devine-Wright's [4] call to marry the social and psychological approaches to the study of social acceptance have been heeded, and Upham et al's [3] interdisciplinary dialogue is taking place. However, our research indicates that this dialogue is primarily taking place at the individual-level interaction between contextual and psychological factors, as is suggested by the framework provided by Perlaviciuite et al., but largely absent any consideration of political motivations for behaviour (let alone considerations of non-behavioural aspects of social acceptance, or attention paid to group dynamics or opposition movements). The risk here, as noted in Section 5.1, is the de-politicization of acceptance issues surrounding energy technology and fuels, especially as they occur in the context of sustainable energy transitions. In that regard, the group six research front seems to be the most focused on these types of contextual/institutional issues and, perhaps unsurprisingly, a group with few connections to the emerging centre in group five.

Yet another observation we can make about the likely future for interdisciplinary dialogue across the field is that, as some researchers within a research front seek to build bridges with neighbouring ones, others in that front may pull away from the emerging interdisciplinary discussion. The disperse shape of group three suggests a case in point. Here we find scholars like Poortinga and Upham building bridges to group five and group six, respectively, but the cluster of articles surrounding Frederiks 2015 (a comprehensive review of explanatory factors underlying residential energy consumption) appears to be pulling away. It seems likely that this research front will eventually pull apart into three future groups one retaining the focus on household energy consumption and environmental behaviour, another looking at individual-level psychological determinants of technological risk perception, and another attempting to bring environmental behaviour concepts to project planning and siting processes.

\section{Conclusion}

We set out in this article to visualize the knowledge domain for the social acceptance of energy technology and fuels. The aim was to supplement existing perspectives and provide fresh insight on the field using global and empirical bibliometric techniques. We identified seven distinct research fronts in the literature and produced maps demonstrating the structure and influence within these networks. . We also identified and characterized the intellectual bases of each research front, demonstrating that there is relatively little overlap in the intellectual heritage of each front, and examined collaboration and interdisciplinary dialogue in an exploration of author-author, author-research front and research frontjournal directed networks.

Our findings indicate that influence in the field is shifting from its historic centre in the study of community acceptance of wind power to the emerging centre focused on combining individual-level contextual and psychological determinants of perceptions and attitudes vis-à-vis large-scale electricity system technologies and/or projects. While the current structure of the literature does not suggest that the three dimensions of social acceptance originally laid out by Wüstenhagen, Wolsink, and Bürer are the primary focus of research efforts, the updated framework found in Upham, Oltra, and Boso's 2015 paper is much more representative.

Finally, much as the latter article noted the difficulty in producing integrated cross-paradigmatic frameworks for an interdisciplinary field, we find that interdisciplinary dialogue was slow to get started, 
and current research fronts still appear to be largely shaped by technological focus and intellectual heritage. While recent publications indicated that interdisciplinary dialogue is taking place, we find the most influential dialogue to be concentrated around individual-level contextual and psychological factors. This raises some concern about the potential de-politicization of social acceptance issues. Furthermore, our findings suggest that as the approach to conceptualization and operationalization of acceptance found in Group five becomes more prominent, existing research fronts may pull apart into two or more separate groups, with one retaining the traditional theoretical and methodological principles of its forbearer.

\section{Works Cited}

[1] P. Sriwannawit, U. Sandström, Large-scale bibliometric review of diffusion research, Scientometrics. 102 (2014) 1615-1645. doi:10.1007/s11192-014-1448-7.

[2] B.K. Sovacool, What are we doing here? Analyzing fifteen years of energy scholarship and proposing a social science research agenda, Energy Res. Soc. Sci. 1 (2014) 1-29. doi:10.1016/j.erss.2014.02.003.

[3] P. Upham, C. Oltra, À. Boso, Towards a cross-paradigmatic framework of the social acceptance of energy systems, Energy Res. Soc. Sci. 8 (2015) 100-112. doi:10.1016/j.erss.2015.05.003.

[4] P. Devine-Wright, Beyond NIMBYism: towards an integrated framework for understanding public perceptions of wind energy, Wind Energy. 8 (2005) 125-139. doi:10.1002/we.124.

[5] P. Devine-Wright, Rethinking NIMBYism: The role of place attachment and place identity in explaining place-protective action, J. Community Appl. Soc. Psychol. 19 (2009) 426-441. doi:10.1002/casp.1004.

[6] D. van der Horst, NIMBY or not? Exploring the relevance of location and the politics of voiced opinions in renewable energy siting controversies, Energy Policy. 35 (2007) 2705-2714. doi:10.1016/j.enpol.2006.12.012.

[7] M. Wolsink, Wind power and the NIMBY-myth: institutional capacity and the limited significance of public support, Renew. Energy. 21 (2000) 49-64. doi:10.1016/S0960-1481(99)00130-5.

[8] M. Wolsink, Entanglement of Interests and Motives: Assumptions behind the NIMBY-theory on Facility Siting, Urban Stud. 31 (1994) 851-866. doi:10.1080/00420989420080711.

[9] M. Aitken, Why we still don't understand the social aspects of wind power: A critique of key assumptions within the literature, Energy Policy. 38 (2010) 1834-1841. doi:10.1016/j.enpol.2009.11.060.

[10] J.J. Cohen, J. Reichl, M. Schmidthaler, Re-focussing research efforts on the public acceptance of energy infrastructure: A critical review, Energy. 76 (2014) 4-9. doi:10.1016/j.energy.2013.12.056.

[11] E. Frederiks, K. Stenner, E. Hobman, The Socio-Demographic and Psychological Predictors of Residential Energy Consumption: A Comprehensive Review, Energies. 8 (2015) 573-609. doi:10.3390/en8010573.

[12] N.M.A. Huijts, E.J.E. Molin, L. Steg, Psychological factors influencing sustainable energy technology acceptance: A review-based comprehensive framework, Renew. Sustain. Energy Rev. 16 (2012) 525-531. doi:10.1016/j.rser.2011.08.018.

[13] G.L. Perlaviciute, L. Steg, Contextual and psychological factors shaping evaluations and acceptability of energy alternatives: Integrated review and research agenda, Renew. Sustain. ENERGY Rev. 35 (2014) 361-381. doi:10.1016/j.rser.2014.04.003.

[14] R. Wüstenhagen, M. Wolsink, M.J. Bürer, Social acceptance of renewable energy innovation: An introduction to the concept, Energy Policy. 35 (2007) 2683-2691. doi:10.1016/j.enpol.2006.12.001. 
[15] K. Borner, C.M. Chen, K.W. Boyack, Visualizing knowledge domains, Annu. Rev. Inf. Sci. Technol. 37 (2003) 179-255. doi:10.1002/aris.1440370106.

[16] K.W. Boyack, R. Klavans, K. Borner, Mapping the backbone of science, Scientometrics. 64 (2005) 351-374. doi:10.1007/s11192-005-0255-6.

[17] H.D. White, K.W. McCain, Visualizing a discipline: An author co-citation analysis of information science, 1972-1995, J. Am. Soc. Inf. Sci. 49 (1998) 327-355. doi:10.1002/(SICI)10974571(19980401)49:4<327::AID-ASI4>3.0.CO;2-4.

[18] B. Hjørland, H. Albrechtsen, Toward a new horizon in information science: Domain-analysis, J. Am. Soc. Inf. Sci. 46 (1995) 400-425. doi:10.1002/(SICI)1097-4571(199507)46:6<400::AIDASI2>3.0.CO;2-Y.

[19] E. Garfield, Citation Indexes for Science: A New Dimension in Documentation through Association of Ideas, Science. 122 (1955) 108-111. doi:10.1126/science.122.3159.108.

[20] M.M. Kessler, Bibliographic coupling between scientific papers, Am. Doc. 14 (1963) 10-25.

[21] H. Small, Co-citation in the scientific literature: A new measure of the relationship between two documents, J. Am. Soc. Inf. Sci. 24 (1973) 265-269. doi:10.1002/asi.4630240406.

[22] V. Blondel, The Louvain method for community detection in large networks, (n.d.). https://perso.uclouvain.be/vincent.blondel/research/louvain.html (accessed September 19, 2017).

[23] C. Chen, CiteSpace II: Detecting and visualizing emerging trends and transient patterns in scientific literature, J. Am. Soc. Inf. Sci. Technol. 57 (2006) 359-377. doi:10.1002/asi.20317.

[24] D.J.D.S. Price, Networks of Scientific Papers, Science. 149 (1965) 510-515.

[25] O. Persson, The intellectual base and research fronts of JASIS 1986-1990, J. Am. Soc. Inf. Sci. 45 (1994) 31-38. doi:10.1002/(SICI)1097-4571(199401)45:1<31::AID-ASI4>3.0.CO;2-G.

[26] C. Chen, F. Ibekwe-SanJuan, J. Hou, The structure and dynamics of cocitation clusters: A multipleperspective cocitation analysis, J. Am. Soc. Inf. Sci. Technol. 61 (2010) 1386-1409. doi:10.1002/asi.21309.

[27] S.A. Morris, G. Yen, Z. Wu, B. Asnake, Time line visualization of research fronts, J. Am. Soc. Inf. Sci. Technol. 54 (2003) 413-422. doi:10.1002/asi.10227.

[28] L.C. Freeman, Centrality in social networks conceptual clarification, Soc. Netw. 1 (1978) 215-239.

[29] B.C. Griffith, H.G. Small, J.A. Stonehill, S. Dey, The structure of scientific literatures II: Toward a macro-and microstructure for science, Soc. Stud. Sci. 4 (1974) 339-365.

[30] D. Toke, S. Breukers, M. Wolsink, Wind power deployment outcomes: How can we account for the differences?, Renew. Sustain. Energy Rev. 12 (2008) 1129-1147. doi:10.1016/j.rser.2006.10.021.

[31] D. Bell, T. Gray, C. Haggett, The "Social Gap" in Wind Farm Siting Decisions: Explanations and Policy Responses, Environ. Polit. 14 (2005) 460-477. doi:10.1080/09644010500175833.

[32] K. Ek, Public and private attitudes towards "green" electricity: the case of Swedish wind power, Energy Policy. 33 (2005) 1677-1689. doi:10.1016/j.enpol.2004.02.005.

[33] S. Jacobsson, A. Johnson, The diffusion of renewable energy technology: an analytical framework and key issues for research, Energy Policy. 28 (2000) 625-640. doi:10.1016/S0301-4215(00)000410.

[34] M. Wolsink, Wind power implementation: The nature of public attitudes: Equity and fairness instead of "backyard motives," Renew. Sustain. Energy Rev. 11 (2007) 1188-1207. doi:10.1016/j.rser.2005.10.005.

[35] C. Gross, Community perspectives of wind energy in Australia: The application of a justice and community fairness framework to increase social acceptance, Energy Policy. 35 (2007) 2727-2736. doi:10.1016/j.enpol.2006.12.013.

[36] M. Johansson, T. Laike, Intention to respond to local wind turbines: the role of attitudes and visual perception, Wind Energy. 10 (2007) 435-451. doi:10.1002/we.232. 
[37] M. Vorkinn, H. Riese, Environmental Concern in a Local Context: The Significance of Place Attachment, Environ. Behav. 33 (2001) 249-263. doi:10.1177/00139160121972972.

[38] C.R. Warren, M. McFadyen, Does community ownership affect public attitudes to wind energy? A case study from south-west Scotland, Land Use Policy. 27 (2010) 204-213. doi:10.1016/j.landusepol.2008.12.010.

[39] A. Hansla, A. Gamble, A. Juliusson, T. Gärling, Psychological determinants of attitude towards and willingness to pay for green electricity, Energy Policy. 36 (2008) 768-774. doi:10.1016/j.enpol.2007.10.027.

[40] B. Roe, M.F. Teisl, A. Levy, M. Russell, US consumers' willingness to pay for green electricity, Energy Policy. 29 (2001) 917-925. doi:10.1016/S0301-4215(01)00006-4.

[41] A. Bergmann, N. Hanley, R. Wright, Valuing the attributes of renewable energy investments, Energy Policy. 34 (2006) 1004-1014. doi:10.1016/j.enpol.2004.08.035.

[42] A.M. Borchers, J.M. Duke, G.R. Parsons, Does willingness to pay for green energy differ by source?, Energy Policy. 35 (2007) 3327-3334. doi:10.1016/j.enpol.2006.12.009.

[43] N. Nomura, M. Akai, Willingness to pay for green electricity in Japan as estimated through contingent valuation method, Appl. Energy. 78 (2004) 453-463. doi:10.1016/j.apenergy.2003.10.001.

[44] N. Zografakis, E. Sifaki, M. Pagalou, G. Nikitaki, V. Psarakis, K.P. Tsagarakis, Assessment of public acceptance and willingness to pay for renewable energy sources in Crete, Renew. Sustain. ENERGY Rev. 14 (2010) 1088-1095. doi:10.1016/j.rser.2009.11.009.

[45] P.C. Stern, New Environmental Theories: Toward a Coherent Theory of Environmentally Significant Behavior, J. Soc. Issues. 56 (2000) 407-424. doi:10.1111/0022-4537.00175.

[46] L.J. Becker, C. Seligman, R.H. Fazio, J.M. Darley, Relating Attitudes to Residential Energy Use, Environ. Behav. 13 (1981) 590-609. doi:10.1177/0013916581135004.

[47] C. Seligman, M. Kriss, J.M. Darley, R.H. Fazio, L.J. Becker, J.B. Pryor, Predicting Summer Energy Consumption from Homeowners' Attitudes, J. Appl. Soc. Psychol. 9 (1979) 70-90. doi:10.1111/j.1559-1816.1979.tb00795.x.

[48] E.M. Rogers, Diffusion of innovations, 4th ed, Free Press, New York, 1995.

[49] W. Poortinga, L. Steg, C. Vlek, Values, Environmental Concern, and Environmental Behavior: A Study into Household Energy Use, Environ. Behav. 36 (2004) 70-93. doi:10.1177/0013916503251466.

[50] W. Abrahamse, L. Steg, C. Vlek, T. Rothengatter, A review of intervention studies aimed at household energy conservation, J. Environ. Psychol. 25 (2005) 273-291. doi:10.1016/j.jenvp.2005.08.002.

[51] I. Ajzen, The theory of planned behavior, Organ. Behav. Hum. Decis. Process. 50 (1991) 179-211. doi:10.1016/0749-5978(91)90020-T.

[52] P. Ashworth, N. Boughen, M. Mayhew, F. Millar, From research to action: Now we have to move on CCS communication, Int. J. Greenh. Gas Control. 4 (2010) 426-433. doi:10.1016/j.ijggc.2009.10.012.

[53] K. van Alphen, Q. van Voorst tot Voorst, M.P. Hekkert, R.E.H.M. Smits, Societal acceptance of carbon capture and storage technologies, Energy Policy. 35 (2007) 4368-4380. doi:10.1016/j.enpol.2007.03.006.

[54] D. van Knippenberg, D. Daamen, Providing Information in Public Opinion Surveys: Motivation and Ability Effects in the Information-and-Choice Questionnaire, Int. J. Public Opin. Res. 8 (1996) 7082. doi:10.1093/ijpor/8.1.70.

[55] C.A. Van der Salm, D. van Knippenberg, D.D.L. Daamen, A critical test of the choice questionnaire for collecting informed public opinions, Qual. Quant. 31 (1997) 193-197. doi:10.1023/A:1004214500745. 
[56] M. de Best-Waldhober, D. Daamen, A. Faaij, Informed and uninformed public opinions on CO2 capture and storage technologies in the Netherlands, Int. J. Greenh. Gas Control. 3 (2009) 322332. doi:10.1016/j.jiggc.2008.09.001.

[57] K. Tokushige, K. Akimoto, T. Tomoda, Public perceptions on the acceptance of geological storage of carbon dioxide and information influencing the acceptance, Int. J. Greenh. Gas Control. 1 (2007) 101-112. doi:10.1016/S1750-5836(07)00020-5.

[58] N.M.A. Huijts, C.J.H. Midden, A.L. Meijnders, Social acceptance of carbon dioxide storage, ENERGY POLICY. 35 (2007) 2780-2789. doi:10.1016/j.enpol.2006.12.007.

[59] B.W. Terwel, F. Harinck, N. Ellemers, D.D.L. Daamen, Going beyond the properties of CO2 capture and storage (CCS) technology: How trust in stakeholders affects public acceptance of CCS, Int. J. Greenh. Gas Control. 5 (2011) 181-188. doi:10.1016/j.ijggc.2010.10.001.

[60] N.F. Pidgeon, I. Lorenzoni, W. Poortinga, Climate change or nuclear power-No thanks! A quantitative study of public perceptions and risk framing in Britain, Glob. Environ. Change. 18 (2008) 69-85. doi:10.1016/j.gloenvcha.2007.09.005.

[61] S.C. Whitfield, E.A. Rosa, A. Dan, T. Dietz, The Future of Nuclear Power: Value Orientations and Risk Perception, Risk Anal. 29 (2009) 425-437. doi:10.1111/j.1539-6924.2008.01155.x.

[62] M. Siegrist, The Influence of Trust and Perceptions of Risks and Benefits on the Acceptance of Gene Technology, Risk Anal. 20 (2000) 195-204. doi:10.1111/0272-4332.202020.

[63] M. Siegrist, A Causal Model Explaining the Perception and Acceptance of Gene Technology, J. Appl. Soc. Psychol. 29 (1999) 2093-2106. doi:10.1111/j.1559-1816.1999.tb02297.x.

[64] C.J.H. Midden, N.M.A. Huijts, The Role of Trust in the Affective Evaluation of Novel Risks: The Case of $\mathrm{CO}_{2}$ Storage, Risk Anal. 29 (2009) 743-751. doi:10.1111/j.1539-6924.2009.01201.x.

[65] P. Menanteau, D. Finon, M.-L. Lamy, Prices versus quantities: choosing policies for promoting the development of renewable energy, Energy Policy. 31 (2003) 799-812. doi:10.1016/S03014215(02)00133-7.

[66] C. Mitchell, D. Bauknecht, P.M. Connor, Effectiveness through risk reduction: a comparison of the renewable obligation in England and Wales and the feed-in system in Germany, Energy Policy. 34 (2006) 297-305. doi:10.1016/j.enpol.2004.08.004.

[67] A. Bergek, S. Jacobsson, B. Carlsson, S. Lindmark, A. Rickne, Analyzing the functional dynamics of technological innovation systems: A scheme of analysis, Res. Policy. 37 (2008) 407-429. doi:10.1016/j.respol.2007.12.003.

[68] G.C. Unruh, Escaping carbon lock-in, Energy Policy. 30 (2002) 317-325. doi:10.1016/S03014215(01)00098-2.

[69] G. Walker, N. Cass, Carbon reduction, "the public" and renewable energy: engaging with sociotechnical configurations, Area. 39 (2007) 458-469. doi:10.1111/j.1475-4762.2007.00772.x.

[70] S. Mourato, B. Saynor, D. Hart, Greening London's black cabs: a study of driver's preferences for fuel cell taxis, Energy Policy. 32 (2004) 685-695. doi:10.1016/S0301-4215(02)00335-X.

[71] M. Ricci, P. Bellaby, R. Flynn, What do we know about public perceptions and acceptance of hydrogen? A critical review and new case study evidence, Int. J. Hydrog. Energy. 33 (2008) 58685880. doi:10.1016/j.ijhydene.2008.07.106.

[72] I. Schulte, Issues affecting the acceptance of hydrogen fuel, Int. J. Hydrog. Energy. 29 (2004) 677685. doi:10.1016/j.ijhydene.2003.09.006.

[73] K. Haraldsson, A. Folkesson, M. Saxe, P. Alvfors, A first report on the attitude towards hydrogen fuel cell buses in Stockholm, Int. J. Hydrog. Energy. 31 (2006) 317-325. doi:10.1016/j.ijhydene.2005.11.008.

[74] M. Saxe, A. Folkesson, P. Alvfors, A follow-up and conclusive report on the attitude towards hydrogen fuel cell buses in the CUTE project-From passengers in Stockholm to bus operators in Europe, Int. J. Hydrog. Energy. 32 (2007) 4295-4305. doi:10.1016/j.ijhydene.2007.07.050. 
[75] D. Diamond, The impact of government incentives for hybrid-electric vehicles: Evidence from US states, Energy Policy. 37 (2009) 972-983. doi:10.1016/j.enpol.2008.09.094.

[76] R.R. Heffner, K.S. Kurani, T.S. Turrentine, Symbolism in California's early market for hybrid electric vehicles, Transp. Res. Part Transp. Environ. 12 (2007) 396-413. doi:10.1016/j.trd.2007.04.003.

[77] D. Potoglou, P.S. Kanaroglou, Household demand and willingness to pay for clean vehicles, Transp. Res. Part Transp. Environ. 12 (2007) 264-274. doi:10.1016/j.trd.2007.03.001.

[78] P. Upham, Applying environmental-behaviour concepts to renewable energy siting controversy: Reflections on a longitudinal bioenergy case study, Energy Policy. 37 (2009) 4273-4283. doi:10.1016/j.enpol.2009.05.027.

[79] W. Poortinga, A. Spence, C. Demski, N.F. Pidgeon, Individual-motivational factors in the acceptability of demand-side and supply-side measures to reduce carbon emissions, Energy Policy. 48 (2012) 812-819. doi:10.1016/j.enpol.2012.06.029.

[80] N.M.A. Huijts, B. van Wee, The evaluation of hydrogen fuel stations by citizens: The interrelated effects of socio-demographic, spatial and psychological variables, Int. J. Hydrog. Energy. 40 (2015) 10367-10381. doi:10.1016/j.ijhydene.2015.06.131.

[81] P. Hartmann, V. Apaolaza, C. D'Souza, C. Echebarria, J.M. Barrutia, Nuclear power threats, public opposition and green electricity adoption: Effects of threat belief appraisal and fear arousal, Energy Policy. 62 (2013) 1366-1376. doi:10.1016/j.enpol.2013.07.058.

[82] D. Bidwell, The role of values in public beliefs and attitudes towards commercial wind energy, ENERGY POLICY. 58 (2013) 189-199. doi:10.1016/j.enpol.2013.03.010.

[83] A. Kontogianni, C. Tourkolias, M. Skourtos, D. Damigos, Planning globally, protesting locally: Patterns in community perceptions towards the installation of wind farms, Renew. Energy. 66 (2014) 170-177. doi:10.1016/j.renene.2013.11.074.

[84] J.E. Carlisle, S.L. Kane, D. Solan, M. Bowman, J.C. Joe, Public attitudes regarding large-scale solar energy development in the US, Renew. Sustain. ENERGY Rev. 48 (2015) 835-847. doi:10.1016/j.rser.2015.04.047.

[85] W. Liu, C. Wang, A.P.J. Mol, Rural public acceptance of renewable energy deployment: The case of Shandong in China, Appl. ENERGY. 102 (2013) 1187-1196. doi:10.1016/j.apenergy.2012.06.057.

[86] J. Kraeusel, D. Moest, Carbon Capture and Storage on its way to large-scale deployment: Social acceptance and willingness to pay in Germany, ENERGY POLICY. 49 (2012) 642-651. doi:10.1016/j.enpol.2012.07.006. 